\title{
DIRECCIÓN DE EMPRESAS
}

\section{MAESTRÍA EN DIRECCIÓN DE EMPRESAS}

FACUlTAD DE CienCias ECONÓMICAS

UNIVERSIDAD NACIONAL DE LA PLATA

Trabajo de tesis para optar al título de Magister

Tema:

COMPETITIVIDAD DE PRODUCTOS EXPORTABLES EN EL MARCO DE UNA RELACIÓN BILATERAL. UN ANÁLISIS SOBRE LA EXPORTACIÓN DE CUEROS ARGENTINOS AL MERCADO ITALIANO

Autor: Carlos Augusto Persico

Director de tesis: Ernesto Fabián Botana

Agradecimiento especial: Claudio Farabola

La Plata, Agosto de 2021 


\section{ÍNDICE}

Introducción 3

1-Presentación del tema de estudio 5

2-Planteamiento de interrogantes, formulación de objetivos y de premisas 9

2.1.- Interrogantes 10

2.2.- Formulación de objetivos general y específicos 10

2.2.1.- Objetivo general 11

2.2.2.- Objetivos específicos 11

2.3.- Planteo de premisas de trabajo 11

3.- Delimitación y justificación del estudio 12

3.1.- Límites del estudio 12

3.2.- Justificación de la temática elegida 14

4.-Marco teórico 15

4.1.- El modelo de la ventaja competitiva de las naciones 16

4.1.1.- Determinantes de la ventaja competitiva 16

4.1.2.- Condiciones de los factores 20

4.1.3.- Condiciones de la demanda 23

4.1.4.- Sectores relacionados y de apoyo 26

4.1.5.- Estrategia, estructura y rivalidad de las empresas 27

4.1.6.- El papel del azar y el rol del Gobierno 28

4.1.7.- La dinámica de la ventaja competitiva de una nación 30

5.- Proceder para el análisis de la información 34

5.1.- Relevamiento y análisis de información 34

$\begin{array}{ll}\text { 5.2.- Esquema de análisis } & 37\end{array}$

5.2.1.- Análisis del escenario competitivo 38

5.2.2.- Análisis de la creación de ventaja competitiva 41

5.2.3.- Perpsectiva desde el fomento de una relación comercial bilateral 44

6.- Resultados del análisis sobre la problemática en estudio 45

6.1.- Análisis del escenario competitivo 46

6.1.1.- Amenaza de ingreso de nuevos competidores 47

6.1.2.- Intensidad de rivalidad entre competidores 50 
Carlos Augusto Persico | Maestría en Dirección de Empresas | FCE-UNLP

6.1.3.- Presión de competidores sustitutos 53

6.1.4.- Poder de negociación de clientes 55

6.1.5.- Poder de negociación de proveedores 58

6.2.- Análisis de la creación de ventaja competitiva 61

6.2.1.- Condiciones de los factores 61

6.2.2.- Condiciones de la demanda 62

6.2.3.- Estrategia, estructura y rivalidad entre empresas 63

6.2.4.- Sectores relacionados y de apoyo 65

6.2.5.- Rol del Gobierno 66

6.3.- Comentarios sobre el perfil competitivo del sector analizado 67

7.- Conclusiones 69

8.- Referencias bibliográficas 78 


\section{Introducción}

La esencia de la competitividad de los países no debe buscarse tanto en el desempeño general de todos los sectores de su economía, sino más bien en el desempeño superlativo de algunos de sus sectores en forma puntual. En este sentido, debería interpretarse que los países que son competitivos, lo son por poseer un desempeño superior en un número limitado de sectores económicos; precisamente, los sectores que se muestran como los puntales de la competitividad nacional.

Esto no quiere decir que el país del que se trate en términos generales no sea competitivo; mas bien todo lo contrario. En realidad, la idea da cuenta de la imposibilidad de que un país sea competitivo en todos los sectores de su economía, dado lo complejo que es cualquier sistema económico nacional e internacional en el mundo actual. La diversidad de factores que hoy determinan la competitividad global hace prácticamente imposible que un mismo país sea competitivo en un gran número de sectores económicos.

En consecuencia, se acepta como idea de competitividad la de que un país sustente su capacidad competitiva en un desempeño superior respecto de un número limitado de sectores. En este sentido, la competitividad nacional se sustentaría en uno o en unos pocos sectores de desempeño superior, con capacidad competitiva de nivel global, mientras que el resto de la economía nacional acompañaría a estos sectores competitivos en tanto base ineludible y necesaria sobre la que sustentar un buen desempeño competitivo global.

Por lo dicho, se entiende que para construir y mantener ventaja competitiva nacional, los países deben apelar al desarrollo específico de una serie de sectores sobre los que, por características distintivas y naturaleza propias del país en cuestión, sea factible construir ventaja, generando por su parte las condiciones necesarias como para que toda la economía pueda acompañar a los sectores que, bajo este esquema de interpretación, pasan a ser los actores esenciales de la competitividad nacional.

Lo antedicho viene a cuento del estudio exploratorio realizado en el presente trabajo final de maestría. En efecto, siendo el sector de la producción ganadera uno de 
los sectores tradicionales que a lo largo de la historia económica argentina pudo disfrutar de ventajas comparativas, existentes en el país, como para llevar adelante su producción, se estima que resulta oportuno indagar en su real capacidad de generar ventaja competitiva, como para poder convertirse en uno de los pilares en los que sustentar la competitividad nacional.

O en otros términos, se puede explorar en la capacidad para que un sector que ha gozado históricamente de ventajas comparativas, pueda registrar un desempeño competitivo superior a escala global a partir de la creación y mantenimiento de ventajas competitivas, y pasar a ser de esa forma un actor relevante del perfil competitivo que pueda alcanzar el país.

Hilando más fino en el concepto actual de competitividad, se puede afirmar también que los sectores competitivos lo son en realidad por la especialización que logran en definir una oferta muy específica, distintiva, de alto valor agregado, y destinada a satisfacer demandas bien segmentadas, con puntuales características. Considerando entonces esta suerte de ventaja competitiva enfocada, es dable indagar en un nicho puntual del sector económico de la ganadería, tal como puede ser la producción de cuero vacuno; e incluso concentrando el análisis en el marco de una relación bilateral entre países con lazos comerciales históricos, como lo son Argentina e Italia.

En consecuencia, enfocando el estudio en una oferta específica del sector ganadero en tanto sector económico con potencial para generar ventaja competitiva, e incrementando el enfoque al considerar a un solo país-cliente, caracterizado en el mundo como un demandante altamente exigente y con estándares de calidad realmente elevados, es que se puede plantear un análisis exploratorio sobre la siguiente cuestión: la exportación de cuero vacuno por parte de Argentina, en tanto producto específico de un sector ganadero con potencial de crear y mantener en el tiempo ventaja competitiva; con destino al mercado italiano, en función tanto de la histórica relación bilateral entre países, como de la condición de demandante altamente exigente para el producto específico cuero vacuno por parte de ese país europeo. 
En función de lo expresado, el presente estudio se compone de una primera sección en la que se presenta el tema de estudio, en línea con lo arriba expresado pero ya referenciando algunos antecedentes teóricos, algunos de los cuales serán profunizados en la sección de marco teórico (cuarta sección del trabajo). Como segunda sección, se plantea la triada de preguntas que impulsaron el estudio, formulación de objetivos general y específico, y propuesta de premisas en el sentido de los resultados que a priori se esperaban alcanzar.

Se expone luego en una tercera sección una serie de precisiones que hacen a la delimitación del estudio, como para asegurar que fuera abordable, considerando los recursos disponibles y la disponibilidad de información de análisis con la que se podía llegar a contar; junto a precisiones sobre la justificación del tema elegido, en el sentido que fuera un tema factible de ser considerado para un trabajo final de programa MBA.

A continuación, y luego de la cuarta sección ya mencionada sobre marco teórico, se expone una quinta para dar detalles sobre cómo se procedió para el análisis de la información que permitió arribar a conclusiones sobre el estudio, cerrando el presente escrito, precisamente, con sus dos últimas secciones, dedicadas la primera de ellas a la presentación de los resultados del análisis sobre la problemática en estudio; en tanto que la sección final cierra lo expuesto con una serie de conclusiones.

Introducido entonces el trabajo final, se presenta la primera sección sobre presentación del tema de estudio.

\section{1-Presentación del tema de estudio}

El nivel de competitividad que pueda alcanzar una nación es uno de los determinantes de cuán desarrollada pueda llegar a ser su economía, entendiendo por competitividad a la capacidad de esa nación de contar con determinados sectores económicos que tengan la condición de ser, precisamente, competitivos a escala global, en el sentido de que detenten y fomenten la creación y mantenimiento de ventajas competitivas (Porter, 1991). 
Esta afirmación invita a reparar especialmente en uno de sus elementos, y es el de que una economía podrá ser realmente competitiva en determinados sectores limitados en su número, por lo que sería inabordable el propósito que pudiera tener una nación de ser competitiva en todos los sectores económicos. En efecto, desde hace más de dos siglos ya se viene proponiendo que la capacidad de una nación de generar riqueza depende precisamente de la capacidad que tenga para tener un desempeño superior en determinados sectores económicos (Smith, [1776] 1994), que puedan canalizar las habilidades distintivas de su fuerza laboral, una disponibilidad particular de recursos y una combinación determinada de todos los factores de la producción.

$\mathrm{Y}$ esta idea se mantiene en el presente, en donde existe consenso general para aceptar que las economías realmente competitivas lo son por poseer, como se dijo, una ventaja competitiva diferencial en puntuales sectores económicos en los que saben demostrar un desempeño superior en términos relativos con otras economías del mundo (Porter, 1991, 2002).

Se cuenta entonces con la idea de que toda nación que pretenda ser competitiva lo será en realidad a través de la competitividad que logre en determinados sectores de su economía. Y esto es particularmente importante de analizar en países en desarrollo, en los que, a esta concepción general de que la competitividad puede darse siempre y cuando esté limitada a algunos sectores, se suma la limitación adicional de la disponibilidad general de recursos en economías subdesarrolladas, en las que es habitual que siempre falte alguna de las condiciones mínimas que puedan impulsar un camino hacia el desarrollo económico (Acemoglu y Robinson, 2013).

Enfocando lo dicho en el contexto específico de la economía argentina, se puede pensar a esta como sumergida desde hace decádas en recurrentes ciclos de crisis que han impedido crear las condiciones necesarias como para contar con una serie de sectores que impulsen el desarrollo de la nación por medio de la explotación de ventajas competitivas de escala global (Gerchunoff y Llach, 2003; Ferrer, 2004). Tradicionalmente, y amparados en la disponibilidad de ventajas comparativas propias del país (Ricardo, [1817] 2010), los sectores relacionados con la explotación agícola y 
ganadera fueron impulsores de relevancia de la economía nacional; aunque también fue en las últimas décadas que ambos tuvieron una evolución desigual.

Por un lado, un sector agrícola pujante logró crear ventaja competitiva, de la mano de una explotación cada vez más intensiva e incorporando en forma paulatina tecnología de producción y gestión para dejar de ser un sector que simplemente se beneficia de las mencionadas ventajas comparativas (Roccatagliata, 2008; Barsky y Gelman, 2008). Por el otro, un sector ganadero que no siguió al mismo tiempo la evolución tecnológica y su adaptación a las nuevas dinámicas del escenario competitivo global, dejando de ser, hace mucho tiempo ya, uno de los impulsores principales de la economía nacional. En otras palabras, el sector ganadero no es hoy uno de los sectores centrales de la economía, como, a poco que se repase su historia (Giberti, 1961), bien lo supo ser en su momento.

En definitiva, fue el sector ganadero el que de ser central en la economía se convirtió en uno caracterizado por sus dificultades actuales para ser competitivo a escala global, con la consecuencia de que esto le ha costado la pérdida de oportunidad de aprovechar los mercados internacionales que para la industria de la producción de ganado vacuno y sus derivados existen en el mundo (Quiroga, 2019).

Y precisamente de las definiciones de este último párafo es que se desprende el problema de investigación planteado en este trabajo. En efecto, una de las actividades del sector ganadero se encuentra en la producción de cueros; y es esta una actividad que no alcanza a aprovechar la disponibilidad de oportunidades estratégicas para un producto que tiene su demanda global en, por caso, la industria de la indumentaria y la marroquinería, o la de los automóviles de alta gama y la de los productos de lujo; sectores todos estos que configuran sus ofertas con un alto valor agregado, y para los que el cuero de ganado vacuno representa uno de sus insumos esenciales.

Además, y tomando en cuenta que estos actores económicos globales de sectores que pueden utilizar al cuero vacuno como insumo de calidad se encuentran concentrados en un grupo limitado de países, existe también la falta de aprovechamiento de oportunidad en la opción estratégica que respresenta el generar 
y/o profundizar relaciones comerciales bilaterales con ellos, que puedan llegar a estimular el desarrollo competitivo del sector con la creación y/o mantenimiento de ventaja de una naturaleza específica.

Entonces, se puede definir al problema de investigación en función de las siguientes pautas:

- En Argentina, el sector ganadero en general no tiene hoy la relevancia sobre la economía del país que supo tener en otros momentos de su historia. Inherente a este proceso de pérdida de relevancia se encuentra el sector derivado de la producción de cuero vacuno.

- El país sigue manteniendo ventajas comparativas derivadas de su configuración geográfica y de otras características puntuales que favorecen el desenvolvimiento en determinado tipo de actividades relacionadas con la producción primaria, las que bien pueden utilizar tales ventajas comparativas para la creación y mantenimiento de las mismas. Se entiende que el sector de la producción de cuero vacuno, es uno de estos sectores favorecidos con la disponibilidad de dichas ventajas.

- Existiría una oportunidad estratégica en una demanda de alta calidad de competidores de nivel y escala global que utilizan al cuero vacuno como uno de los insumos principales de su proceso de configuración de la oferta, existiendo por tanto la opción estratégica de construir y reforzar vínculos comerciales entre, por un lado, productores locales de cuero vacuno en tanto insumo de calidad, $y$, por otro, productores de perfil global consumidores del mismo.

- En función del grado de concentración geográfica de productores globales que utilizan al cuero vacuno como insumo, existiría además la posibilidad de construir ventaja competitiva para el sector productivo de la mano de relaciones bilaterales que la impulsen, relaciones que pueden construirse a nivel de gobiernos nacionales entre países 
productores (el cuero vacuno de origen argentino como insumo) y demandantes de perfil competitivo global (las industrias concentradas en un conjunto limitado de países que utilizan al cuero vacuno como uno de sus insumos esenciales).

- Tomado en cuenta que en el mercado italiano se encuentra un nicho específico de sectores que utilizan cuero vacuno de alta calidad como insumo, se interpreta que sobre una relación bilateral con este país se podría fomentar una ventaja competitiva duradera para el sector productivo de dicho producto derivado de la actividad ganadera.

En virtud de lo expresado, es que se plantea como tema de estudio el ya sugerido en el título del presente trabajo: un análisis sobre la exportación de cueros argentinos al mercado italiano desde una perspectiva de competitividad de productos exportables, en el marco de una relación bilateral argentino-italiana. En consecuencia, y presentado de esta forma el tema de estudio, se procede ahora a exponer las preguntas que impulsaron a este último, junto a la formulación de objetivos y de hipótesis/premisas que sirvieron de guía como para poder concretarla.

\section{2.-Planteamiento de interrogantes, formulación de objetivos y de premisas}

En esta segunda sección se expone la triada compuesta por las preguntas que impulsaron estudio, los objetivos generales y específicos que fueron formulados para guiarlo, y las hipótesis/premisas que se plantearon a modo de resultados que eran esperados a priori. Cada una de estas tres cuestiones (preguntas, objetivos e hipótesis/premisas) fueron analizadas y decididas manteniendo un debido alineamiento lógico entre todas ellas. 


\section{1.-Interrogantes}

Se exponen tres preguntas útiles para direccionar el estudio, cada una de las cuales fueron además disparadores de los elementos del objetivo general y de la formulación de los objetivos específicos, y se integran en forma lógica con las hipótesis/premisas de trabajo que también se exponen en este apartado.

Las preguntas son:

- ¿Es posible analizar un escenario competitivo en el marco de una relación comercial bilateral entre dos países como Argentina e Italia?

- ¿Se pueden identificar factores descriptivos que permitan evaluar la competitividad del sector de exportación de cueros de Argentina?

- ¿Existe algún proceder de análisis de datos que pueda ser utilizado para evaluar el nivel de competitividad del sector elegido como objeto de estudio?

- ¿Es factible proponer líneas de acción que fomenten la creación y mantenimiento de ventaja competitiva por parte del sector de exportación de cueros en Argentina?

\section{2.-Formulación de objetivos general y específicos}

Para la formulación de objetivos se siguió como lineamiento lo prescripto al respecto por Caballero Romero (2014), en el sentido de plantear un objetivo general que contenga elementos que luego se profundicen en la formulación de objetivos específicos, que no excedan a aquél, y que den cuenta de: i) una realidad a describir (el mercado de exportación de cueros argentinos), ii) un marco referencial (la relación bilateral entre Argentina e Italia), iii) una identificación de factores descriptivos (los factores que dan cuenta de competitividad de la cadena de comercialización del cuero argentino), iv) un tipo de análisis (la aplicación de modelos analíticos universalmente aceptados), y v) una sugerencia de solución de mejora de la problemática (proponiendo fortalecimiento de la cadena y remoción de eslabonamientos débiles). 


\subsection{1.-OBJETIVO GENERAL}

Analizar la relación comercial bilateral entre Argentina e Italia para la comercialización de cueros argentinos con destino a ese país europeo, indagando en sus características e identificando factores que hacen a las fortalezas y debilidades de la cadena de valor agregado y de exportación.

\subsection{2.-OBJETIVOS ESPECÍFICOS}

- La realidad y el marco referencial. Analizar la cadena de comercialización de cueros argentinos con destino al mercado de exportación de Italia, en el marco de la relación comercial bilateral que mantienen ambos países.

- Identificación de factores descriptivos. Identificar factores relevantes determinantes de las fortalezas y debilidades de la cadena para lograr posicionar el producto exportable en el mercado de destino, explorando en ventajas competitivas que puedan existir en el país de origen como para que eso sea posible

- Tipo de análisis. Abordar el análisis haciendo uso de dos modelos conceptuales universalmente aceptados como herramientas analíticas.

- Sugerencia de solución. Proponer una solución a la problemática planteada, que sugiera un fortalecimiento de la ventaja competitiva que pueda existir en la cadena, y una remoción de factores que puedan estar debilitándola.

\section{3.-Planteo de premisas de trabajo}

Completando la triada preguntas-objetivos-hipótesis/premisas, se formularon en su momento las siguientes hipótesis/premisas en función de los resultados que eran esperados al inicio del estudio, las que a su momento se expresará en qué medida pudieron haberse comprobado.

- Hipótesis/premisa 1: Se puede identificar una serie de factores que permiten analizar la situación competitiva del sector de exportación de cueros argentinos con destino a Italia. 
- Hipótesis/premisa 2: Es posible utilizar como herramientas de análisis modelos universalmente aceptados de análisis de la competitividad de sectores productores exportados en el marco de una relación bilateral.

- Hipótesis/premisa 3:A partir del análisis de competitividad que se pueda identificar, es factible proponer una serie de lienamientos de acción que ayuden a una creación, mejora y/o sostenimiento de ventaja competitiva por parte del sector exportador tomado como objeto de estudio.

Planteada la triada preguntas de investigación, objetivos general y específicos e hipótesis/premisas de trabajo, se establecen en el próximo apartado la justificación del problema de investigación y los límites que se establecieron para que el estudio fuera abordable en el marco de una tesis de programa MBA.

\section{3.- Delimitación y justificación del estudio}

Se establecieron los límites necesarios para hacer abordable la investigación en el marco de un trabajo final de Maestría en Dirección de Empresas; más aún tomando en cuenta que es muy amplia la problemática en general de la competitividad internacional de una nación, de allí que se haya tomado lo muy específico de un único sector de la economía con actividades de exportación.

Por su parte, en la justificación, se enuncian las pautas por las que se considera que lo investigado es factible de ser considerado como tema de investigación de un trabajo para optar a un título de MBA.

\section{1.- Límites del estudio}

Los siguientes ítems marcan la delimitación que fuera establecida para crear el ámbito estricto bajo el cual se desarrolló el estudio: 
- Delimitación sectorial. Se consideró la actividad de la exportación de cueros vacunos en las distintas opciones posibles en cuanto al valor agregado incorporado al producto exportable.

- Delimitación de alcance geográfico. A fin de considerar una cadena de valor completa que incluyera oferta y demanda del sector económico elegido, se escogió la relación bilateral comercial entre Argentina e Italia como para enfocar sobre ella el estudio. Por lo que, tomando en cuenta lo sectorial y lo geográfico, el estudio resultó ser de la actividad de la exportación de cueros vacunos dentro de la relación bilateral comercial de Argentina en tanto productor/exportador e Italia comprador/importador.

- Delimitación temática. Del sector económico y de la relación bilateral que se eligieron, se enfocó el estudio exclusivamente en los factores que se identificaron como principales determinantes de la ventaja competitiva existente en aquél. En otras palabras, el estudio se enfocó exclusivamente en el análisis de existencia, creación y/o mantenimiento de ventaja competitiva del sector productor de cuero vacuno argentino y en el específico ámbito de la relación bilateral argentino-italiana.

- Delimitación temporal. La investigación se enfocó en un momento específico de tiempo, y más allá de exponer alguna referencia histórica referida a la situación de la relación bilateral entre los dos países, no es una investigación que aborde el análisis de la evolución a lo largo del timpo de esta última.

- Delimitación de proceder metodológico. El análisis de existencia, creación y/o mantenimiento de ventaja competitiva en el sector económico y en la relación bilateral específica que se consideró, se realizó haciendo uso exclusivamente de modelos analíticos universalmente aceptados y por tanto aceptación generalizada en cuanto a su pertenencia. En este sentido, el estudio no implicó avanzar 
en propuestas enriquecedoras de dichos modelos, sino que se limitó a utilizarlos como las herramientas de análisis que son.

\section{2.- Justificación de la temática elegida}

Respecto de la justificación del tema de investigación, se enuncian los siguientes ítems:

- El tema elegido y el problema de investigación planteado son factibles de ser utilzados en una tesis de MBA por ser pertinentes a varios de los módulos incluidos en la currícula del programa, en cuanto a temáticas generales que hacen, por caso, al análisis de escenarios económicos, la creación y mantenimiento de ventajas competitivas, la identificación de factores presentes en una relación comercial de exportación e importación, y los ámbitos regulatorios de tales relaciones. Por tanto, el tema de tesis elegido se considera apropiado para un trabajo de tesis destinado a optar por el título de Magíster en Dirección de Empresas.

- El tema resulta un aporte original en la medida en que no se encontraron antecedentes de investigación que analicen el problema de investigación en el sector económico elegido desde la perspectiva de utilizar para ello herramientas de análisis universalmente aceptadas; y más aún, tampoco se encontraron antecedentes que de una y otra forma analicen la competitividad del sector exportable de cuero vacuno con destino a Italia considerando que este país es uno de los más importantes consumidores del producto del mundo.

- El tema elegido satisfizo la condición indicada al autor del presente para la realizar su trabajo final de maestría, en el sentido de considerar especialmente temáticas en las que de una u otra forma se encontrara inmerso o tuviera acceso seguro a los datos/información necesarios para un análisis. Al respecto, el autor pudo hacer uso de acceso a información no disponible en forma pública de la relación bilateral entre países y, en forma personal, al equipo de conducción de la Cámara de 
Carlos Augusto Persico | Maestría en Dirección de Empresas | FCE-UNLP

Comercio Argentino-Italiana, fuente muy valorable de información de análisis y, como se verá, grupo de enfoque sobre el que se pudo relevar los datos esenciales para el análisis de los resultados del estudio.

\section{4-Marco teórico}

Se expone en este apartado el encuadramiento teórico del trabajo realizado, necesario para ofrecer una interpretación al estudio planteado. En este sentido, la postura teórica consistirá en repasar los conceptos salientes del esquema de Porter de diamante de la competitividad nacional, herramienta analítica generalmente aceptada para evaluar un objeto de estudio como el que se ha elegido, esto es, la competitividad internacional de un sector específico de una economía nacional en el marco de una relación bilateral entre países donde se ubican productores y consumidores. Sobre cada elemento en que consiste este esquema, se hará una mención o interpretación de como se entiende que se aplica a la problemática en estudio. 


\section{1.- El modelo de la ventaja competitiva de las naciones}

La evolución teórica del concepto de competitividad de una nación tuvo un hito importante en la aparición del modelo de ventaja competitiva de las naciones (Porter, 1991), que supuso un aporte esencial para entender cómo es que los países logran crear y sostener en el tiempo ventaja competitiva, amparándose en ello en el desempeño competitivo de una serie limitada de sectores con potencial para aspirar por su propia configuración en el ámbito específico de la nación de que se trate - a tener un desempeño superior desde una perspectiva global.

El modelo, que a pesar del paso de los años mantiene su plena vigencia, tiene la capacidad de plantear una propuesta teórica integral desde un enfoque sistémico, para explicar cuáles son los elementos determinantes de la ventaja competitiva de una nación y cómo es que esos elementos se relacionan en forma dinámica entre sí. La perspectiva sistémica implícita en el modelo (Bunge, 1995, 2012) es lo que permite analizar tanto el perfil general de una nación en el escenario competitivo global como indagar en cada una de las variables que determinan su desempeño competitivo. Así, se pueden estudiar al mismo tiempo las fuerzas que componen un escenario de competencia de escala global (Porter, 1981), al mismo tiempo que se lo hace sobre la capacidad de un sector competitivo específico de generarse un desempeño superior a partir de la creación y sostenimiento en el tiempo de ventaja competitiva (Porter, 1986).

El aspecto saliente del modelo es, precisamente, el concepto de diamante competitivo, por medio del cual se identifican un conjunto de determinantes que por su condición e interrelación mutua hacen a la competitividad de una nación. En las próximas líneas se hace una breve mención sobre él.

\subsection{1.- DETERMINANTES DE LA VENTAJA COMPETITIVA}

La ventaja competitiva de una nación hay que buscarla en realidad en el desempeño competitivo de los sectores económicos puntuales que la sustentan, que dada la configuración de la economía nacional podrán ser unos y no otros, aunque siempre 
limitados en número. Serán los determinantes de la competitividad de estos sectores lo que explican la ventaja competitiva nacional. En este sentido, analizar los determinantes del perfil competitivo del sector productor de cuero vacuno en Argentina permite dar cuenta de la contribución de este a una ventaja competitiva de la economía del país.

Contextualizando el sector objeto de estudio dentro del modelo teórico que se está proponiendo para ello, a la pregunta de “¿por qué alcanza una nación el éxito global en un sector económico en particular?", puede responderse con que "la respuesta se encuentra en cuatro atributos genéricos de una nación que conforman el entorno en que han de competir las empresas locales y que fomenta o entorpece la creación de ventaja competitiva" (Porter, 1991, p. 110). Estos cuatro atributos genéricos que se mencionan son en realidad los que deben identificarse como determinantes de la ventaja competitiva.

Considerando el sector en estudio, se trataría de los determinantes de la ventaja competitiva de la economía argentina que podrían estar siendo fomentados por la actividad específica de la producción y exportación de cuero vacuno.

En la figura 1 se presenta en esquema gráfico los determinantes de la competitividad, y en los ítems que la suceden una resumida mención de ellos, que se complementará con un tratamiento en los siguientes apartados contextualizándolos en función del sector de la exportación de cuero vacuno.

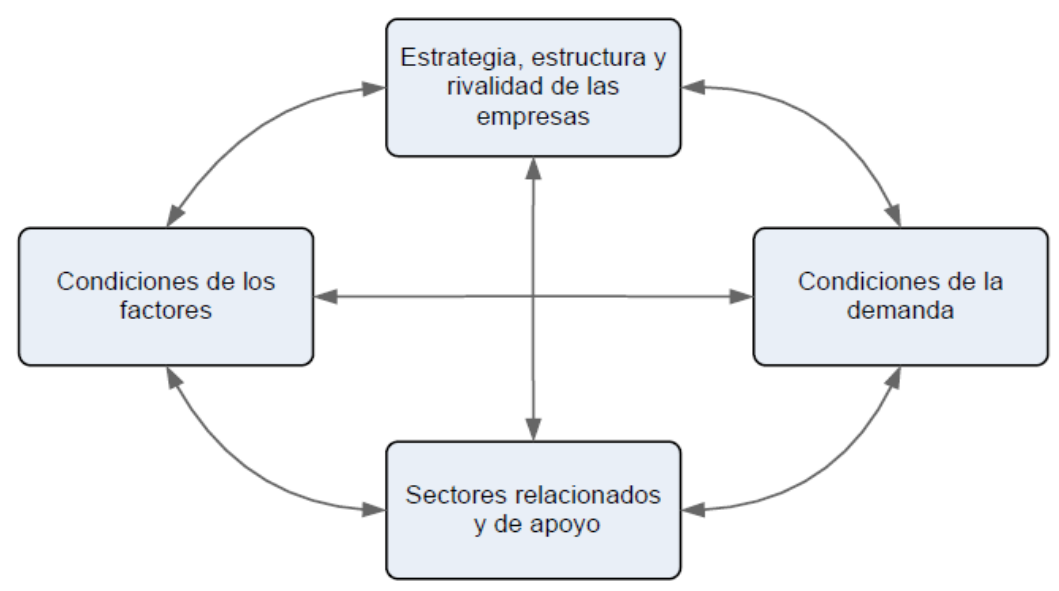

Figura 1. Fuerzas de un escenario competitivo 
Determinantes de la ventaja competitiva:

- Condiciones de los factores. Determinante referido a la posición de país en cuanto a la disponibilidad, por caso, de recursos naturales, recursos humanos especializados e infraestructura necesaria para competir a escala global en un sector dado.

- Condiciones de la demanda. Referido a la naturaleza de la demanda interior del sector en cuanto a fomento de su nivel de competitividad, y a las características de la demanda exterior en cuanto a oportunidad de crear y/o profundizar ventaja competitiva.

- Sectores relacionados y de apoyo. Sobre la presencia en el escenario competitivo doméstico de sectores proveedores y otros relacionados que sean por su parte competitivos internacionalmente.

- Estrategia, estructura y rivalidad de las empresas del sector. Referido a las condiciones en las que se crean, crecen y se gestionan las empresas participantes del escenario competitivo del sector considerado.

El modelo sostiene que, según sea la disposición de estos cuatro determinantes, una nación puede crear y sostener una ventaja competitiva en uno o más sectores específicos cuando logra alcanzar una combinación favorable de ellos. Esto no implica que deba registrar un desempeño óptimo en todos ellos, pero sí en cambio que sepa interpterar cual es la más efectiva forma en que pueda combinar los determinantes para extraer de tal combinación el máximo potencial competitivo posible.

Por el contrario, se considera que no podrá sustentarse una ventaja competitiva basada en solo uno o dos de los determinantes, por generar esta forma un tipo de ventaja muy precaria, habituales en sectores económicos y naciones muy dependendientes de recursos naturales o de tecnologías o técnicas poco avanzadas.

Y precisamente en esto último puede repararse al considerar el sector de la producción de cuero vacuno en Argentina, con un desempeño basado fundamentalmente en ventaja sustentada en la condición de los factores, por ser uno 
de los puntos distintivos del país las condiciones naturales para la producción de ganado, sin alcanzar con ello la posibilidad de crear una ventaja competitiva sustentable al existir carencias en la potencialidad de los restantes determinantes.

Dispuestos los determinantes, el modelo considera luego dos variables que se adicionan a ellos. Por un lado, el papel del azar, entendiendo por tal a la ingerencia en los distintos escenarios competitivos de eventos imprevistos, trascendentes y de impacto económico, sea en un sector específico o en la economía en general, pero que resultan ser imposibles de predecir, o bien existen sobre ellos señales demasiado débiles como para ser tenidos en cuenta con una ponderación probabilística importante.

En el sector considerado, el papel atribuible al azar podría encontrarse, por caso, en cambios intempestivos en la demanda mundial que llevarán a tener que descartar sustitutos sintéticos del cuero legítimo, o un acontencimiento tan improbable como trascendente que anulará la capacidad de producción de competidores de otros países rivales.

Por otro lado, como segunda variable adicionada, se encuentra el rol desempeñado por el Gobierno, en tanto actor de relevancia en sus funciones elementales de regular, controlar y gestionar políticas de Estado, quien en tales funciones bien puede tanto fomentar como retrasar la creación y/o sostenimiento de ventaja competitiva. Sobre el rol del Gobierno y en lo específico del sector económico que se está considerando, valga como adelanto la referencia a las disímiles políticas aplicadas a lo largo de la historia económica del país sobre la producción primaria de vacunos y sus derivados (Giberti, 1961; Rapoport, 2010).

Entonces, se tiene un modelo en el que los cuatro determinantes junto a las dos variables adicionales, considerando todo en un conjunto, se relacionan entre sí en forma sistémica (Bunge, 1995, 2012), conformando lo que se conoce como diamante de la ventaja competitiva nacional.

En los próximos apartados se presentarán consideraciones sobre estos determinantes y variables adicionales, para luego expresar una breve mención al 
modelo funcionando dentro de la dinámica del diamante competitivo, con alguna contextualización respecto del sector económico que se está considerando.

\subsection{2.- CONDICIONES DE LOS FACTORES}

El primero de los determinantes de la ventaja competitiva de una nación es la condición de sus factores de producción, entendiendo por tal a la cantidad y calidad de sus recursos productivos, y a la capacidad para mantenerlos, perferccionarlos o generar nuevos. Se entiende que, bajo los parámetros del modelo, una nación será competitiva cuando pueda priorizar la asignación de recursos siempre escasos en los sectores que por su productividad aseguren el mejor uso de ellos.

Es cierto que estas son consideraciones ya contempladas en los tradicionales enfoques de ventaja absoluta y ventaja comparativa (Ramírez y Wallace, 1998); sin embargo, el modelo de la ventaja competitiva va más allá en el análisis al indagar y proponer las herramientas para identificar qué tipo de factores son los de mayor calidad y sobre cuáles tiene un país la habilidad distintiva para, a partir de ellos, generar competitividad de escala global.

De esta manera, es como se propone que los factores más apropiados para la ventaja competitiva no serán los heredados sino más bien los generados por la propia dinámica de la economía doméstica.En otras palabras, que no serán los ya existentes sin la intervención de un proceso previo de generación de valor sino más bien aquellos que requieren una deliberada acción, y con continuidad en el tiempo, de creación, mantenimiento y mejora del perfil competitivo de determinados sectores.

Como exponentes de este tipo de factores de baja y alta calidad respecto de la capacidad de promover ventaja competitiva, valen dos ejemplos: como de baja calidad, los recursos naturales con los que cuente un país cuando ellos son extraídos y/o explotados sin mayor agregación de valor (Acemoglu y Robinson, 2013), como buen ejemplo es el de la producción primaria de ganado vacuno en tanto temática general del presente trabajo; y como de alta calidad, la disponibilidad de recursos 
humanos de alta formación y especializados en cadenas de valor agregado de sectores económicos específicos con capacidad exportadora y de creación de ventaja competitiva global, como para el caso de Argentina bien puede mencionarse el caso de la industria del software (López y Ramos, 2008).

Respecto de la calidad de los factores, el modelo llega a proponer que la abundancia de los de baja calidad (se insiste, extraídos u explotados sin mayor agregación de valor) puede incluso degradar la competitividad, ya que en tal situación no se generaría un proceso en el que determinadas desventajas en factores productivos disparan en la economía mecanismos de innovación y mejora destinados a suplir las carencias, que en casos así se encontrarían relacionadas con externalidades positivas para el conjunto de sectores económicos (Ohmae, 1985, 1990).

Además, el modelo resulta un avance respecto de lo que debe considerarse como factores, abandonando la tradicional enumeración desde la economía como disciplina, en cuanto a definir a los factores como de trabajo, capital y tierra (Ferguson y Gould, 1990), para avanzar hacia una concepción teórica más de acuerdo con tiempos actuales y que reflejan mejor todo el andamiaje teórico de la creación y sostenimiento de ventaja competitiva nacional. Así, agrupa factores bajo categorías relacionadas con i) recursos humanos, y en esto no sólo la tradicional consideración de mano de obra, sino también las personas que basan su productividad en la aplicación de conocimientos científicos, técnicos, etc.; ii) recursos físicos, desde los tradicionales tierra, agua y minerales hasta la consideración de factores climáticos y hasta posiciones geopolíticas del país en el contexto internacional; iii) recursos de conocimiento, básicamente, el stock de know-how que tenga una nación y la capacidad para generarlo y crearlo nuevamente en forma permanente; iv) recursos de capital, y en esto no sólo el stock de capital existente en la economía sino la flexibilidad, capacidad de crédito y posicionamiento de la nación en el contexto financiero internacional; e v) infraestructura, entendiendo por tal desde el conjunto de recursos duros como los sistemas de transporte, redes de comunicación, asistencia sanitaria, etc., hasta blandos como pueden ser instituciones culturales o incluso el atractivo de determinada nación como un buen lugar para vivir y trabajar. 
Esta nueva consideración de factores de producción resulta apropiada para evaluar la competitividad del sector productor de cuero vacuno, con características puntuales al respecto que responde a: i) recursos humanos con el potencial de agregar el valor que hoy escasea en la cadena productiva integral del sector, por ser una de las habilidades distintivas del país la producción de talento y la formación de profesionales; ii) recursos físicos que son también sello distintivo para la producción de ganado vacuno, sustentándose en la tradicional ventaja comparativa del país en cuanto a recursos naturales relacionados con el sector primario de la economía (Belini y Korol, 2012); iii) recursos de conocimiento, relacionado con lo dicho respecto de recursos humanos, y la capacidad del país de generar conocimiento y adoptar rápidamente cuerpos teóricos y nuevas prácticas en todo tipo de disciplinas; iv) recursos de capital, siendo posiblemente el punto más débil de toda la disponibilidad de recursos, por los problemas endémicos de la economía argentina de insertarse en el contexto económico internacional y las dificultades permanente de asegurar fuentes de financiamiento (Gerchunoff y Llach, 2003), problemática que bien puede en parte explicar la no capitalización y desarrollo de cadena de producción del cuero, anclada en un grado de desarrollo de hace décadas; y en cuanto a v) la infraestructura, si bien con sus limitaciones en cuanto a adaptabilidad, el sector cuenta con la disponibilidad de recursos suficientes que siempre han servido a la producción de carne vacuna, en cuanto a la infraestructura de puertos, vías terrestres y navegables, y demás elementos de conectividad física con el resto del mundo (Roccatagliata, 2008).

Por otra parte, otra consideración relevante del modelo de Porter es la indicada como de jerarquía de los factores, pudiendo ser ellos, por una parte, básicos o avanzados, y por otra, generalizados o específicos. Los factores básicos serían los heredados por una nación, los que existen por sí mismos; resultando también factor básico la mano de obra no especializada y la infraestructura elemental. Por el contrario, los factores avanzados serían los que para su disponibilidad requieren prolongados procesos de innovación y fuertes inversiones, como la infraestructura digital, el personal altamente capacitado, las instituciones académicas y los centros de investigación. En este sentido, el modelo propone que una ventaja competitiva de 
orden superior, más sólida, más estable y más difícil de igualar es la que se construye sobre factores avanzados, porque dotan a una nación de una especificidad única en el tipo de factores que dispone y aplica en sus procesos productivos, distinguiéndose de esa manera de aquellas naciones que sólo hacen uso de su factores básicos, heredados, sin mayor desarrollo.

Por otra parte, en la otra distinción por jerarquías, los factores generalizados son los que están al servicio del conjunto de los sectores de la economía, sin distinción específica por sus características o sus aplicaciones (ej.: red de carreteras, red decomunicaciones); en cambio, los factores específicos comprenden aquellos que son destinados a su asignación altamente especializada en sectores y procesos productivos muy puntuales (disponibilidad de recursos humanos con conocimientos muy avanzados y especializados, laboratorios de investigación sobre ramas muy concretas de las ciencias, etc.).

Complementando lo anterior, una ventaja de orden superior se logrará entonces sustentando la economía no sólo en factores avanzados sino ahora también en los muy específicos. Al respecto de todo esto, se puede afirmar que el sector de la producción y exportación de cuero argentino sigue encontrándose hoy fuertemente inclinado por la disponibilidad y uso de factores básicos y generalizados, producto de la tradicional explotación de ventaja comparativa del país y la no existencia de un proceso continuo de inversión y desarrollo de factores de mayor jerarquía.

\subsection{3. - CONDICIONES DE LA DEMANDA}

Al referirse a condiciones de la demanda, el modelo se refiere en primer término a demanda interior, que en primera instancia crea, con sus particularidades y exigencias, precisamente las condiciones para que determinado sector de la economía de un país pueda generar y/o sostener ventaja competitiva. La lógica de este proceso sería: i) una demanda interna de determinado sector productivo, al ser muy exigente en sus hábitos de consumo, genera empresas preparadas, entrenadas y muy entendidas en la forma de satisfacer tal nivel de demanda; ii) con el paso del tiempo, este impulso crea 
una serie de conocimientos, prácticas y capacidades por parte de las empresas como para, internacionalizando ese know-how o esas prácticas de un saber hacer, trasladar el dominio en el mercado interno hacia los mercados del exterior.

Las cualidades de la demanda interna son entonces uno de los pilares sobre los que se construye ventaja competitiva. En este sentido, tres atributos genéricos de la demanda interior serían los particularmente significativos, en sus palabras: i) la composición de la demanda interior; ii) la magnitud y pautas de crecimiento de tal demanda, y iii) los mecanismos mediante los cuales se transmiten a los mercados del exterior las preferencias de una demanda doméstica. En otras palabras, se trata de evaluar en qué medida y a qué ritmo un sector puede internacionalizar las condiciones de la demanda interna que le hayan permitido desarrollarse y especializarse en la satisfacción de los requerimientos de ella.

Reparando en estas tres características y enfocando la consideración en el contexto del sector productor de cuero argentino, se puede expresar sobre la composición de la demanda interior, que será un factor impulsor de ventaja competitiva cuanto más específicamente segmentada se encuentre tal demanda; esto es, que esa demanda interna cuente con segmentos de mercado de características y exigencias únicas y fácilmente reconocibles, compuestos por consumidores entendidos y exigentes en sus demandas, conocedores al detalle de todos los atributos que debe proveer una oferta de calidad. En este sentido, será también relevante que las necesidades y deseos de los cosumidores domésticos sean precursoras respecto de las correspondientes a los mercados de otros países, algo así como que la demanda doméstica "lidere" el nivel de exigencias respecto de los mercados del exterior.

En lo relacionado al sector bajo estudio, puede afirmarse que la demanda interna del cuero argentino no guarda las características sugeridas por el modelo en consideración, puesto que poco puede promover ventaja competitiva sobre el producto cuero argentino cuando no existe una industria desarrollada y/o suficientemente amplia de la moda, los artículos de lujo, la producción de vehículos de alta gama o bien la marroquinería de estándares internacionales; lo que desde el 
vamos limita el potencial de la demanda interna como fuerza impulsora para la creación de ventaja competitiva (Ungaro, 2010; Martini, 2019).

Respecto de la magnitud y pautas de crecimiento de la demanda interior, resulta importante destacar en principio el tamaño de esa demanda, en el sentido de que cuanto más grande sea el mercado interno más posibilidad dará de aprovechar economías de escala no sólo en los procesos productivos, sino sobre todo en las fases de investigación y desarrollo de nuevos productos y en las inversiones necesarias en capacidad industrial e infraestructura.

Luego, será importante también que la demanda esté constituida por un gran número de consumidores, para de esa manera asegurar una gran diversidad y desarrollo de nuevas exigencias, las que por el contrario podrían "congelarse" en caso de que ese número sea escaso, con un altamente probable retraso en el desarrollo de nuevas exigencias. Además, la demanda interiorserá fuente de ventaja competitiva cuánto más rápidamente se sature, impulsando de esa manera a las empresas del sector a conseguir una visión global que les permita salir a competir por los mercados del exterior en pos de remover el limitante de crecimiento del mercado doméstico.

Sobre el sector bajo estudio, vale en parte lo dicho respecto de la composición de la demanda, el no desarrollo en cuanto a grado de exigencia de ella va de la mano con la escasa magnitud que en el medio local tienen los artículos que como insumo principal usan cuero natural de alta calidad, lo que por su parte determina la condición de que la demanda esté lejos de encontrarse saturada en el mercado doméstico.

Por último, sobre el tercer atributo de la demanda interior para ser fuente de ventaja competitiva, se puede decir que estaría dado por las condiciones en que ella pueda ser internacionalizada por parte de los productores locales. Esto será posible si las empresas logran que las condiciones de los mercados internos "traccionen" la demanda hacia los mercados del exterior, en un proceso que dependerá de cuán móviles internacionalmente o cuán internacionalizados estén algunos de los consumidores domésticos más importantes, o bien qué grado de influencia puedan tener estos sobre sus pares del exterior, a quienes así puedan trasladarles las 
características o exigencias propias del mercado interno y que son conocidas por las empresas. Lo dicho sobre composición de demanda y magnitud del mercado interno complementa con lo que puede pensarse para este atributo: la demanda interna de cuero vacuno no estaría en condiciones de "traccionar" con su impulso una creación o un crecimiento de una demanda internacional altamente segmentada y exigente respecto del producido local.

\subsection{4.- SECTORES RELACIONADOS Y DE APOYO}

Este tercer determinante propuesto como impulsor de ventaja competitiva estáreferido a la presencia, dentro de un país, de sectores proveedores o auxiliares del sector competitivo que se esté considerando y que cuenten ya con ventaja competitiva propia. Esto es, si un sector llamado a crear ventaja competitiva se encuentra relacionado con sectores conexos y auxiliares que ya la poseen, la propia lógica de la relación funciona como impulsor válido y de relevancia de tal ventaja, del sector original y de sus sectores conexos.

La lógica de este factor de la competitividad estaría en la actitud de sectores que intentan crear ventaja de escala global, quienes en forma preferente armarían su "cluster" utilizando proveedores, sectores conexos y de apoyo que ya cuenten con un recorrido internacional y que conozcan las particularidades de mercados globales en cada uno de los específicos sectores en que se desempeñen.

De este modo, y en forma similar a lo ya mencionado como ideal para la cuestión del factor demanda, parte de la creación de ventaja competitiva se sustenta en el "traslado" hacia mercados del exterior de las condiciones imperantes en el escenario competitivo doméstico, del que todo el ámbito productivo relacionado con el sector que se esté considerando ya conoce las particularidades y las prácticas apropiadas para un desempeño de aceptable nivel competitivo.

En otras palabras, se puede afirmar que es muy relevante para el desempeño competitivo internacional de un sector, el que todo el ámbito competitivo doméstico en el que esté inmerso sepa y pueda trasladarse a un escenario competitivo 
internacional, independientemente de que luego el sector central considerado llegue a tener la capacidad de crear su propio ámbito de similar naturaleza pero con actores internacionales.

La idea de un ecosistema económico o sistema en red sería aplicable a la consideración de este determinante, en el sentido de que en torno al sector que se esté considerando exista toda una interrelación sistémica entre los distintos componentes de un escenario competitivo doméstivo, que por su buen desempeño bien tendrían el potencial de trasladar la lógica del sistema a un ámbito competitivo global.

Considerando en forma particular el sector de cuero vacuno, se puede contextualizar lo de este determinante analizando en qué medida colabora todo el macrosector de la producción bovina en la potencial creación de ventaja competitiva para lo particular de la exportación de cuero, con el detalle puntual de cuán relevante puede resultar todo el escenario doméstico en torno a la producción primaria de ganado vacuno, el que, por su dimensión, bien puede traccionar sin gran esfuerzo al sector más específico del cuero (Castaldo et al., 2006).

\subsection{5.- ESTRATEGIA, ESTRUCTURA Y RIVALIDAD DE LAS EMPRESAS}

El cuarto y último determinante de la ventaja competitiva de un sector está relacionado con las características del escenario competitivo de las empresas que, en el ámbito doméstico, forman parte de él. El grado de rivalidad existente entre empresas, y la forma en que estas se encuentren estructuradas y el tipo de estrategias que lleguen a desplegar, determinará el potencial competitivo de todo el sector para crear ventaja; doméstica en primer términio, internacional después.

Por el lado de las estrategias, la posibilidad de crear ventaja competitiva comenzará en una situación en que las empresas tengan por sus propósitos el de convertirse en actores de un escenario competitivo global, ya que si en cambio solo aspiran a dominar el escenario doméstico, poco harán por crearse para sí las condiciones necesarias para convertirse en competidores globales. 
De mismo modo con la forma de estructuración de las empresas. Si en una primera fase de un proceso de internacionalización puede no ser necesario contar con estructuras adecuadas para el abastecimiento de un mercado internacional, sí desde un inicio debe contar en sus propósitos con el debido desarrollo organizacional que asegure condiciones para un salto a futuro a condiciones suficientes para operar como competidor global. Además, la interrelación entre empresas dentro del escenario doméstico actúa como incentivo para que, por imitación, los competidores directos de un sector se sientan impulsados a desarrollarse en ese sentido a un ritmo similar.

Por último, la tercera consideración que para este determinante destaca el modelo consiste en el grado de rivalidad registrado en el escenario donde compiten las empresas de un sector en particular, en el que existiría relación entre una enérgica rivalidad doméstica entre empresas, y la capacidad del sector que ellas componen para crear y sostener ventaja competitiva internacional. En pocas palabras, cuanto mayor grado de rivalidad entre empresas, mayor estímulo para que cada una de ellas responda a las exigencias del escenario y de esa forma "colabore" en crear condiciones competitivas para todo el sector.

En lo específico del contexto del sector productor de cuero vacuno, puede mencionarse sobre la incidencia de este determinante el modesto grado de rivalidad del sector productivo, tanto por la escaza cantidad de actores en el escenario como por lo accesorio del producto considerado para sus cadenas de valor, por ser el cuero producto derivado de la producción principal representada en la carne y sus principales derivados. En este sentido, el sector productor se ha revelado en términos históricos como poco competitivo, caracterizado por actores sin pretensiones de internacionalizarse $y$, por el contrario, enfocados fundamentalmente en mercados domésticos (Salvador, 2013).

\subsection{6. - EL PAPEL DEL AZAR Y EL ROL DEL GOBIERNO}

Más allá de los cuatro determinantes principales, el modelo se completa, como ya se dijo, con la consideración de dos elementos para, todo junto, consituir el 
diamante de la ventaja competitiva. Se trata de dos elementos que no deben considerarse como determinantes genéricos de ventaja, pero sí como factores influyentes en la condición que estos lleguen a tener. Esto es, son dos elementos que, sin llegar a calificarse de determinantes directos, influyen en forma indirecta en el desempeño competitivo de una nación respecto de uno o más sectores. Como se adelantó, estos elementos adicionales son el papel del azar y el rol desempeñado por el Gobierno.

Respecto del azar, se debe tomar en cuenta por la influencia que debe atribuírsele en el desempeño competitivo de una nación, máxime al considerar los acontecimientos que son altamente infrecuentes y que tiene un gran impacto económico cuando ocurren (Taleb, 2014). Lo imprevisto tiene que ver con que sean prácticamente imposibles de predecir, por lo cual no pueden ubicarse dentro de los parámetros que una nación puede incluir en una planificación deliberada de su ventaja competitiva.

Y precisamente por lo imprevisto es que tampoco pueden considerarse como determinantes, puesto que nada puede hacerse sobre ellos en el sentido de "gestionarlos" para que ocurran de una u otra forma. Cuando ocurren, ocurren, sin más, y solo queda afrontar las consecuencias de lo ocurrido, sea en forma de aprovechar la oportunidad o bien de neutralizar la amenaza, en función de que el hecho en cuestión sea bueno o malo para la posición competitiva de un país y/o de los sectores competitivos existentes en él.

Sobre el rol desempeñado por el Gobierno, en el esquema del modelo se le debe atribuir el rol de facilitador o inhibidor de la creación de ventaja competitiva. No se le atribuye, como bien puede apreciarse que hacen otras propuestas (Coriat, 1997), un rol central en la construcción de un perfil competitivo, sino solo de acompañamiento, con la instrumentación de políticas públicas que bien pueden fomentar la ventaja, aunque no, se insiste, determinarla. 


\subsection{7.- LA DINÁMICA DE LA VENTAJA COMPETITIVA DE UNA NACIÓN}

La dinámica de la ventaja competitiva de una nación se configura a partir de la consideración de los cuatro determinantes y los dos factores adicionales que se han visto. Y lo crítico del modelo está precisamente tanto en el desempeño sobre cada uno de los determinantes como en la relación sistémica que los cuatro, junto a los dos factores adicionales, mantienen entre sí.

En efecto, esto es lo que se conoce como diamante de la competitividad (Figura 2), que tomará determinada configuración según cual sea la posición en cada determinante de la nación de la que se trate, en cómo le afecten los acontecimientos azarosos, y en cómo sea el rol del Gobierno promoviendo o inhibiendo la creación y/o sostenimiento de ventaja competitiva.

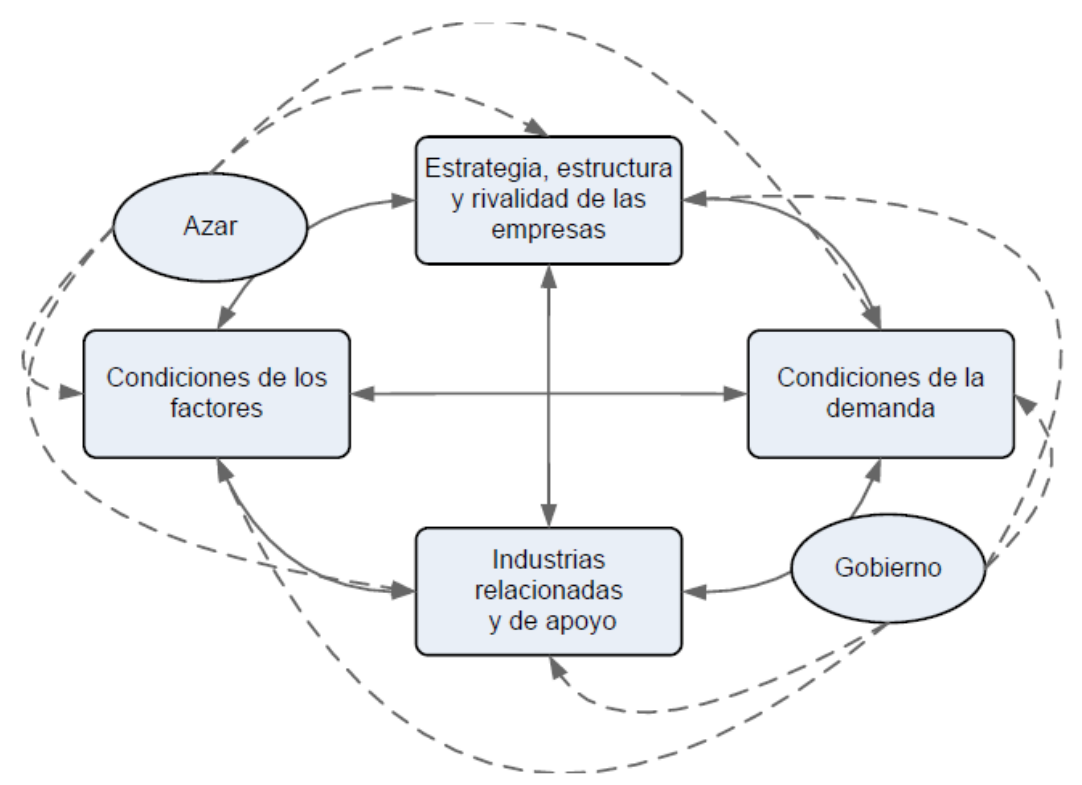

Figura 2. Esquema del diamente competitivo determinante de ventaja competitiva

Por caso, el sector analizado en el presente trabajo tendrá determinada configuración de su diamante competitivo en función de cómo sea el comportamiento puntual del país en cuanto a condición de los factores, condiciones de la demanda, sectores relacionados y de apoyo, y rivalidad competitiva entre actores; y todo ello, en función también de cuales sean las políticas públicas en general y las particulares destinadas al sector, junto a la influencia que lleguen a tener los acontecimientos imprevistos. 
En esta línea, el diamante trabajaría potenciando sus componentes y creando así una lógica virtuosa de creación y/o sostenimiento de ventaja competitiva; o bien en sentido inverso, cuando las condiciones de los elementos y las interrelaciones que mantienen entre sí sean disfuncionales para tal creación, caso en el que la propia lógica de funcionamiento del diamante no impulsaría sino que degradaría la ventaja competitiva que podría haberse construido.

En síntesis, y como característica del "funcionamiento" del diamante competitivo, cuando el círculo es virtuoso, se impulsa la creación y sostenimiento de ventaja competitiva; mientras que, por el contrario, cuando se registra una lógica de círculo vicioso, eso acelera la erosión de la ventaja y la consecuente pérdida de competitividad.

Relacionado con esto último del "funcionamiento inverso" del diamante competitivo, es oportuno mencionar al respecto causas de la degradación de ventaja competitiva en alusión al contexto específico del sector que se está considerando. En este sentido, y siguiendo las prescipciones del modelo, se pueden mencionar causas específicas de la degradación de ventaja o la imposibilidad de crearla; a saber:

- Deterioro de la condición de los factores. Proceso por el cuál el sector económico deja de tener la condición de generar y enriquecer sus factores de producción, por determinadas razones: pérdida de capacidad de innovación, reducida inversión en creación de factores, disminución en la calidad de los mismos, incrementos de costos, etc. Se registraría en el sector analizado en la falta de innovación para crear valor local a la producción primaria de cuero vacuno, o a la alta dependencia de factores primarias o de la industria "madre" de producción de carne vacuna.

- Disparidad entre las necesidades locales y la demanda mundial. Aquí el proceso degenerativo se dispara cuando comienza a crearse una brecha entre las exigencias y/o características de los consumidores locales (la demanda doméstica) y los de otras naciones (demanda internacional). Esto revierte el proceso virtuoso por el cuál la demanda interna debe traccionar a la internacional en pos de crear ventaja competitiva. Reparando en el 
sector considerado, desde el vamos se estaría en presencia de disparidad entre características de la demanda, por no haberse podido alcanzar siguiera un nivel similar a lo que es la demanda global en cuanto a exigencias respecto de la calidad y usos del producto.

- Los consumidores locales dejan de ser exigentes. Una razón hasta complementaria de la anterior, ya que ahora la demanda interna no sólo se disocia de la internacional sino que comienza a perder impulso, transformándose en una fuerza que pierde la capacidad de generar los procesos de innovación en la oferta que siempre ayudan a impulsar la ventaja competitiva. En forma similar, sobre el sector considerado se estaría hablando de una demanda doméstica que no solo pierde sino que siquiera pudo, en términos históricos, llegar a tener impulso.

- El cambio tecnológico lleva a apremiantes desventajas en factores especializados o a la necesidad de nuevos sectores de apoyo de los que se carece. Se trata en este caso de un proceso degenerativo a raíz de las consecuencias sufridas por cambios profundos en las tecnologías base de los procesos productivos, que pueden llegar a desposicionar a los sectores económicos creándoles necesidades urgentes de dominar nuevas tecnologías y de desechar parte de las que hasta ese momento dominaban, con la exigencia adicional de tener que crear nuevas redes de sectores conexos y de apoyo. Tal esfuerzo, demasiado exigente, puede provocar sin más la pérdida total de ventaja competitiva por parte de los sectores afectados. Respecto de esta causa, tradicionalmente el sector se ha visto relegado en cuanto a la adopción de tecnología, productiva o incluso de gestión, para estar a la altura de competidores internacionales.

- Determinados objetivos de rentabilidad afectan el ritmo de inversiones necesarias para mantener ventajas competitivas. En este caso se trata de una readecuación de objetivos, primando los que implican rápidos retornos sobre inversiones en desmedro de objetivos estratégicos con retornos de lenta maduración, pero necesarios para crear los cimientos de una ventaja 
competitiva sólida. Una rápida readecuación de objetivos en este sentido puede generar una igualmente veloz e inevitable pérdida de competitividad. Y aquí cabe mencionar lo general para sectores competitivos en la economía argentina, en la que las recurrentes crisis e inestabilidades económicas llevan habitualmente a los actores económicos a privilegiar los rápidos retornos sobre capitales invertidos en desmedro de inversiones que lenta maduración y potencial más sólido en función de la creación de una ventaja competitiva, algo que en general demanda un tiempo prolongado.

- Descenso en la rivalidad doméstica de las empresas. Siendo la rivalidad entre empresas de un mismo sector uno de los impulsores más potentes de la ventaja competitiva del mismo, esta se degradará por cualquier cuestión que reduzca tal grado de rivalidad. Al disminuir la rivalidad entre empresas el sector económico pierde el acicate para los procesos de innovación y mejora continua, degradando la condición de todo el diamante competitivo. Las causas de disminución en el grado de rivalidad pueden ser varias, entre ellas, la dominación del sector por parte de uno o dos actores, las prácticas colusivas que atentan contra la competencia, las estrategias empresarias de fusiones y adquisiciones, la instrumentación de políticas de Estado proteccionistas respecto de sectores ineficientes o el éxito económico sostenido de todo un sector que "adormece" las capacidad de innovación y mejora. Respecto del sector considerado, vale sobre esto mencionar dos cuestiones; por un lado, no ha sido históricamente un sector de muchos actores y rivalizando fuertemente entre sí, por lo que el determinante de rivalidad entre empresas ya de por sí se presentaría débil; y por otro, a esto se le puede sumar la consideración de que, en general, en los sectores relacionados con la producción primaria suele haber unos pocos actores que son los que concentran la oferta del producto hacia mercados internacionales, con lo que, todos ellos, tienen más estímulos de no rivalizar que de tomar 
actitudes de elevado perfil competitivo que podrían impulsar, por las externalidades positivas de la rivalidad, la competitividad de todo el sector

Presentado el esquema teórico del trabajo, se expone ahora la sección para dar detalle de la forma en que se procedió para el análisis de datos disponibles.

\section{5-Proceder para el análisis de información}

\section{1.-Relevamiento y análisis de información}

Se utilizó como fuente principal de información la existente en la Cámara de Comercio Italiana en la República Argentina (CCIRA), institución que compila todo tipo de datos relevantes sobre los más variados sectores del comercio y de la industria, que participan, o tienen potencial de hacerlo, de relaciones comerciales bilaterales entre Argentina e Italia.

El autor del presente trabajo tuvo acceso a la información de CCIRA contando además, como aquí mismo se describirá, con la posibilidad de trabajar en el análisis de los datos y en la interpretación de la problemática con las autoridades y/o referentes comerciales de dicha institución.

En CCIRA se reúne información que se considera útil para una buena gestión y/o seguimiento del comercio bilateral italo-argentino, y no solo de los sectores que en concreto explican la relación comercial entre las dos naciones, sino también de los que, por características sectoriales específicas o por la naturaleza de la relación entre los países, tienen el potencial del vínculo comercial existente desde hace décadas entre Argentina e Italia.

El sector elegido para la realización del estudio es parte de los que en la CCIRA son calificados como de potencial latente para aprovechar oportunidades que la relación bilateral puede brindarles, en el sentido de que si bien hoy no explican un volumen de negocios de elevada magnitud, sí cuenta con todas las características como para poder hacerlo a futuro. 
En concreto, el relevamiento de información consistió en un trabajo del autor dentro mismo del ámbito de CCIRA, en contacto tanto con autoridades y/o referentes calificados, como por medio del acceso a información existente en la institución.

Al respecto, se pudo conformar con dichas autoridades y/o referentes un grupo de enfoque (Hernández Sampieri et al., 2014), con el que se trabajó bajo las siguientes pautas:

- Se conformó el grupo con la presencia de Claudio Farabola (Gerente General CCIRA) como vocero, junto a sus colaboradores en calidad de reperentes/opinantes calificados, con quienes se realizó una serie de sesiones sobre la tematica planteadas.

- Se realizaron tres sesiones, las que se desarrollaron según la siguiente lógica:

o Primera sesión: se presentó la problemática en estudio y se describieron cuáles eran los propósitos del trabajo que se estaba realizando, analizando luego un panorama inicial del sector comercial implicado y de las características del mismo en la relación bilateral italo-argentina.

- Segunda sesión: se describió y analizó el esquema para evaluar la información pertinente, contextualizándolo en la realidad del sector estudiado en tal relación bilateral

- Tercera sesión: se valorizaron los ítems del esquema de análisis propuestos, con los que se obtuvo el insumo esencial para obtener los resultados del estudio llevado a cabo y poder así arribar a las conclusiones que fueron respuesta a los objetivos previamente formulados.

- La dinámica de funcionamiento del grupo de enfoque que se pudo conformar, respondió a la siguiente lógica: 
- El autor del presente actuó de moderador y de guía de las conversaciones, intentando en todo momento respetar una suerte de "agenda" con las temáticas a tratar en cada sesión.

- Fue presentado el esquema de análisis, discutiendo sobre el grado de pertinencia de cada ítem que contenía, en función del sector económico que se estaba tratando en el marco puntual de la relación comercial bilateral. Los opinantes/referentes acordaron sugerencias de qué ítem podían ser más trascendentes en un análisis e incluso prescribieron la supresión de algunos incluidos en una versión inicial del esquema de análisis.

- Se planteó un debate abierto, fomentado por el autor/moderador, para discutir en forma profunda y acordar en general las valuaciones a otorgar a cada ítem contenido en el esquema de análisis. En otras palabras, se planteó un debate abierto y profundo para llegar a acuerdos al momento de valuar cada una de las variables cualicuantitativas incluidas en el esquema de análisis.

- Con la guía del autor/moderador, se repasaron en conjunto todas las variables cuantitativas y cualitativas del esquema de análisis y se valorizó a cada una de ellas.

En forma complementaria, se concretaron tres sesiones con el titular de la sede La Plata de CCIRA, en las que se desarrollaron i) una entrevista en profundidad para analizar la problemática planteada de la competitividad del sector productor de cuero argentino en la relación comercial bilateral italo-argentina, y ii) un intercambio de opiniones sobre las técnicas de análisis de datos y sobre las conclusiones posibles que el autor del presente podía ensayar con ellos, repasando además el resultado de las sesiones llevadas a cabo con el grupo de enfoque.

Tanto las sesiones con el grupo como las entrevistas con el titular de la sede local de CCIRA, tuvieron como complemento contactos directos, por vías no tan formales, entre el autor del presente trabajo y algunos de los referentes, a fin de evacuar dudas 
o contextualizar conceptos al momento de "pasar en limpio" la información que fuera relevada. El relevamiento de datos, sea por las sesiones formales, las entrevistas o los contactos directos, se llevó a cabo en el período comprendido entre los meses de mayo y agosto de 2020 .

\section{2.-Esquema de análisis}

El esquema de análisis utilizado en el estudio resultó de una combinación de esquemas universalmente aceptados si se trata de analizar la competitividad de sectores económicos y la configuración de escenarios competitivos. En el caso que aquí ocupa, lo decidido al respecto consistió en generar un esquema para poder analizar la competitividad del sector productor de cuero argentino en el ámbito específico de una relación bilateral entre dos países; productor uno, y demandante el otro. La definición de tal esquema consistió en:

- Considerar uno de los esquemas tradicionales y universalmente aceptados, como es el de Porter sobre análisis estructural de sectores económicos (Porter, 1981; Hax y Majluf, 1997);

- Considerar luego un esquema complementario al anterior, también ya tradicional y universalmente aceptado, el también de Porter sobre creación y sostenimiento de ventaja competitiva de una nación por el desempeño de algunos de sus sectores económicos (Porter, 1991; Moon et al., 1995; Cho\& Moon, 2000);

- Combinar ambos equemas previos para constituir uno solo, aplicable a la problemática en estudio, considerando además conceptos teóricos pertinentes vistos por el autor en los módulos del plan de estudios del MBA Administración empresaria, Desarrollo de negocios y Estrategia comercial y competitiva.

Respecto del esquema en sí, resultó como producto uno que permitió analizar el sector en estudio desde dos dimensiones: 
- La del escenario competitivo que afronta el sector productor de cuero vacuno ante una estrategia de exportación dentro del ámbito puntual de una relación comercial bilateral entre dos países;

- La de creación y sostenimiento de ventaja competitiva para poder desempeñarse con efectividad en tal escenario;

- Todo esto, desde la visión de una institución -como CCIRA-que tiene por objeto fomentar la relación comercial bilateral argentino-italiana.

\subsection{1.- ANÁLISIS DEL ESCENARIO COMPETITIVO}

La dimensión del escenario competitivo se sustenta en factores que hacen a las condiciones en que se da el grado de competitividad entre actores de un mismo sector económico. En el caso que se estudió, sobre el potencial exportador de un sector específico dentro del marco de una relación bilateral, se consideró escenario económico todo el ámbito que engloba dichas relación; esto es, tanto las condiciones domésticas como las internacionales que afectan a la competitividad global como a las circunstancias en que un sector desde un país produce y exporta, y en otro existen los clientes que consumen lo producido y exportado.

Esta dimensión se basa en la tradicional propuesta de Porter que define cinco factores que hacen a un escenario competitivo. Para el presente caso de estudio, se repite, se toman tales factores desde una perspectiva internacional inherente a una relación comercial bilateral entre un país productor/exportador y otro consumidor/importador.

Para cada uno de los cinco factores, se definieron una serie de ítems/variables, tomando como referencia lo original del esquema de Porter, suprimiendo algunas pocas variables que el grupo de opinantes calificados consideró como no aplicables para el análisis que se les proponía.

El funcionamiento del esquema desde esta dimensión del escenario competitivo es el siguiente: cada ítem/variable fue calificado con un valor disponible dentro de un rango de 1 a 5, siendo 1 el valor asignado como el más bajo grado de competitividad 
posible del ítem/variable que se esté considerando, y 5 como el valor del más alto grado de competitividad. Bajo esta lógica, luego del análisis y valorización, cada factor registra grados de competitividad, determinado por la valorización que recibieron los ítems/variables que lo componen y la suma de todos ellos. Sumando luego el grado (valor) de los cinco factores, se obtiene un grado general para todo el escenario económico, analizado en tanto situación atractiva para explotar la oportunidad de exportación.

El valor obtenido para todo el escenario (se insiste, el valor de la suma de los cinco factores, los que por su parte son resultado de la suma de cada ítem/variable de cada factor), se coteja en un rango de valores predeterminados que indican lo atractivo que sea el escenario en función del perfil competitivo del sector económico en estudio, definido por el análisis y valorización del grupo de opinantes calificados.

Se exponen entonces los factores a considerar, que por su parte fueran expuestos en el marco teórico, con cada uno de los ítems/variables que lo componen, junto al detalle de los rangos predeterminados para considerar alto atractivo, medio atractivo o bajo atractivo del escenario competitivo, en función del perfil del sector económico, determinado por la posición registrada ante cada ítem/variable.

\section{- Amenaza de ingreso de nuevos competidores}

○ Ítems/variables

- Economías de escala

- Desventaja de costos y recursos

- Efectos en la curva de aprendizaje

- Preferencia de marca

- Requerimiento de capital

- Acceso a canales de distribución

- Políticas reguladoras

- Aranceles y restricciones comerciales

- Acceso a materias primas

- Rangos de valuación de atractividad/perfil competitivo

- Alto: + de 36 puntos 
Carlos Augusto Persico | Maestría en Dirección de Empresas | FCE-UNLP

- Medio: entre 18 y 36 puntos

- Bajo: - de 18 puntos

- Intensidad de la rivalidad entre competidores

o Ítems/variables

- Cantidad de competidores

- Crecimiento de la demanda

- Baja de precios

- Costo de sustitución bajo

- Pérdida de posición de empresas

- Barrera de egreso altas

- Productos indiferenciados

- Rangos de valuación de atractividad/perfil competitivo

- Alto: + de 28 puntos

- Medio: entre 14 y 28 puntos

- Bajo: - de 14 puntos

- Presión de competidores con sustitutos

○ Ítems/variables

- Mejora de la funcionalidad

- Facilidad de acceso

- Precio

- Rangos de valuación de atractividad/perfil competitivo

- Alto: + de 12 puntos

- Medio: entre 6 y 12 puntos

- Bajo: - de 6 puntos

- Poder de negociación de los clientes

- Ítems/variables

- Participación en la facturación total

- Costo de sustitución

- Diferenciación del producto 
- Concentración de compradores

- Relación con la calidad

- Disponibilidad de información

- Amenaza de integración

- Nivel de utilidades

- Rangos de valuación de atractividad/perfil competitivo

- Alto: + de 32 puntos

- Medio: entre 16 y 32 puntos

- Bajo: - de 16 puntos

- Poder de negociación de los proveedores

- Ítems/variables

- Concentración de proveedores

- Importancia del productor/exportador como cliente

- Costos de sustitución

- Amenaza de integración

- Importancia de los insumos

- Inexistencia de oferta de sustitutos

○ Rangos de valuación de atractividad/perfil competitivo

- Alto: + de 24 puntos

- Medio: entre 12 y 24 puntos

- Bajo: - de 12 puntos

\subsection{2.- ANÁLISIS DE LA CREACIÓN DE VENTAJA COMPETITIVA}

Valorizados los ítems/variables identificados como relevantes respecto del caso estudiado, se analizó el potencial de creación de ventaja competitiva del país, para el sector específico considerado, y en el marco muy puntual de la relación bilateral tomada como límite de lo estudiado. Dicho análisis consistió en la valoración por parte de los opinantes calificados de aquel potencial para la creación de ventaja, desde la perspectiva del modelo de diamante competitivo presentado en la sección teórica. 
En otras palabras, lo analizado respecto del escenario competitivo se evaluó desde la perspectiva del diamante competitivo, por medio de un análisis cualitativo complementario de lo que surgiera al considerar los rangos de valuación de atractividad/perfil competitivo. En este otro caso, se definieron una serie de valores posibles a tomar para las variables consideradas en el diamante competitivo, con igualmente cinco posiciones de valores posibles, pero ahora definidos como de valorización cualitativa; esto es, para cada variables se pudo atribuir una valorización de potencial competitivo: i) Alto; ii) Medio Alto; iii) Medio; iv) Medio Bajo y v) Bajo.

Tal como se hiciera para los ítems/variables del escenario competitivo, se presentan los ítems/variables de cada elemento del diamante competitivo, que en la sección sobre resultados del análisis serán valorizados en función de los rangos cualitivos recién mencionados.

Se recuerdan como elementos del diamante competitivo a: i) Condiciones de los factores; ii) Condiciones de la demanda; iii) Estrategia, estructura y rivalidad de las empresas; iv) Industrias relacionadas y de apoyo; v) Azar y vi) Rol del Gobierno. Tomando en cuenta que sobre el elemento Azar no es posible asignar ningún valor que indique a priori su ponderación como para ser determinante de la ventaja competitiva, es incluido siendo parte del esquema analítico, pero no se asigna por tanto ningún valor sobre él.

Por lo dicho, en la siguiente enumeración se presentan los ítems/variables de cada elemento del diamante competitivo con su valorización respecto de potencial competitivo:

\section{- Condiciones de los factores}

- Calidad de las materias primas

○ Disponibilidad áreas para crianza de animales

- Infraestructura para faena

- Infraestructura para transporte

- Infraestructura de puertos de exportación

- Interreaciones entre industria cárnica y de curtiembre 
O Instituciones de investigación y desarrollo

- Capacidad organizativa/productiva de productores pecuarios

- Capacidad de la producción pecuaria para agregar valor a la producción de cueros

- Potencial de crecimiento de la producción de cueros

\section{- B-Condiciones de la demanda}

- Nivel de exigencia de la demanda local respecto de la calidad de los cueros

- Potencial de crecimiento de la demanda local

- Nivel de exigencia de la demanda italiana de cueros argentinos

- Potencial de crecimiento de la demanda italiana de cueros argentinos

- Nivel de diversidad del tipo de industrias demandantes actuales o potenciales de los cueros argentinos

- Existencia en el mercado italiano de productos sustitutos a los cueros argentinos

\section{- C-Estrategia, estructura y rivalidad entre empresas}

- Existencia de concentración o dispersión en el poder relativo de los productores locales de cuero (muchos o pocos productores que se reparten las cuotas de mercado)

- Grado de rivalidad entre productores en pos de ganar cuotas de mercado a expensas de rivales competitivos

- Grado de integración de cadena productiva de la producción de cueros

- Capacidad instalada y grado de utilización de cadena productiva

- Asimilación de tecnología para la producción y comercialización de cueros argentinos

- Perfil económico-financiero de los principales actores del sector (empresas de gran envergadura, pequeños productores, etc.)

\section{- D-Sectores relacionados y de apoyo}

- Nivel de desarrollo de sectores locales proveedores de insumos y servicios a la actividad de producción/comercialización de cueros

- Nivel de desarrollo de sectores radicados en Italia proveedores de insumos y servicios a la actividad de producción/comercialización de cueros. 
- Nivel de calidad ofrecida por las estructuras de logística y transporte para el traslado de cuero desde el punto de producción hasta el puerto de exportación

- Nivel de calidad ofrecida por las estructuras de logística y transporte para el traslado de cuero desde el puerto de exportación hasta destino final en clientes italianos

- Nivel de servicios de administración aduanera

- Nivel de servicios bancarios que asistan al proceso de producción/exportación

- Instituciones de investigación científica al servicio de la producción/exportación

\section{- E-Rol del Gobierno}

○ Presión impositiva

- Sistema de aranceles a la exportación

- Políticas de promoción de la actividad productora de cueros

- Nivel de servicios de organismos públicos al servicio de la cadena de producción/exportación

- Existencia/proyectos/gestión de acuerdos comerciales en general o bilaterales que promuevan la exportación de cueros argentinos

- Nivel de relaciones comerciales entre Argentina-Italia y Argentina-Unión Europea

Entonces, el análisis de cada una de las fuerzas del escenario competitivo, se completa con el análisis de cada una de las dimensiones del diamante competitivo, como para identificar en conjunto un perfil competitivo definido para el sector estudiado dentro de la puntual relación comercial bilateral.

\subsection{3. - PERSPECTIVA DESDE EL FOMENTO dE UNA RELACIÓN COMERCIAL BILATERAL}

Las dos dimensiones del escenario competitivo y de la creación de ventaja competitiva se analizan a través de lo que se define como perspectiva desde la función de fomento de una relación comercial bilateral, que en los hechos no es otra cuestión que la 
perspectiva puntual adoptada, entre las muchas que se podrían haber elegido, para analizar la problemática en estudio con el herramental analítico definido.

En términos prácticos, se adoptó la perspectiva de una institución formal que es nexo entre productores y clientes mediante un rol de fomento de una buena relación comercial entre dos países, lo que supuso el análisis de la problemática por parte de opinantes calificados de tal institución, con resultado para el análisis en la forma de una valorización de cada uno de los ítems que componen el esquema definido, y que permitieron arribar a una interpretación puntual de lo que estaba en estudio.

A partir de la discusión y valorización de cada uno de los ítems/variables del esquema por parte de los opinantes calificados, en el marco de las sesiones de grupo de enfoque realizadas, se obtuvieron los resultados del análisis que son expresados en el siguiente apartado.

En concreto, como proceder para el análisis de información, se consideraron los lineamientos prescriptos por una técnica universalmente aceptada para el análisis de un escenario competitivo y el potencial dentro de él para crear ventaja competitiva de alcance internacional, y se los puso en práctica para analizar en forma puntual un sector muy específico de la economía dentro del marco de una relación bilateral específica entre dos países. Todo ello, con las limitaciones del caso en cuanto a la disponibilidad de información, algo que se circunscribió a lo aportado por opinantes calificados, definidos como tal en función del rol desempeñado en la institución encargada de impulsar relaciones comerciales dentro de la mencionada relación bilateral entre países.

\section{6-Resultados del análisis sobre la problemática en estudio}

Se presenta en esta sección la información relavada ya analizada bajo los esquemas utilizados para un análisis del escenario competitivo y del diamante de la ventaja competitiva del sector en estudio. La forma de presentar la información responde a una lógica de semaforización en función de los rangos de valores posibles tomados por 
los ítems/variables que fueran definidos. En el primer caso (6.1.-Análisis del escenario competitivo), se toman los rangos de valores predefinidos para conformar tres estados posibles de perfil competitivo que puede tomar el sector respecto de cada una de las cinco fuerzas del escenario competitivo. La información se presenta agrupada en subsecciones para cada fuerza, con valor general alto (semaforización verde), medio (amarillo) o bajo (rojo) que corresponda, producto del comportamiento puntual sobre cada componente de cada fuerza. Por su parte, para cada fuerza, se definen sendos rangos de valores que determinan la graduación. Esquemáticamente, esto se expone en cuadros analíticos, cuyo análisis se complementa con una descripción respecto de características/atributos del sector en lo específico de cada elemento de cada fuerza (ej.: se comienza con la mención del elemento economías de escala de la fuerza competitiva amenaza de ingreso de nuevos competidores).

En el segundo caso (6.2.- Análisis de la creación de ventaja competitiva), se mantiene la lógica de semaforización, en este caso para cada componente de cada una de las cinco cuestiones que hacen al diamante competitivo (ej.: se comienza con calidad de materias primas de las condiciones de los factores), y asignando cada componente a un rango específico dividiendo los valores cualitativos pasibles de ser asignados según la siguiente lógica: perfil competitivo alto o medio-alto, rango verde; medio, rango amarillo; y medio-bajo y bajo, rango rojo.

\section{1.- Análisis del escenario competitivo}

En este apartado se expone entonces el análisis de las cinco fuerzas en virtud del relevamiento de datos realizado, recordando que se trata de las fuerzas amenaza de ingreso de nuevos competidores, intensidad de rivalidad entre competidores, presión de competidores sustitutos, poder de negociación de clientes y poder de negociación de proveedores. Los datos relevados se presentan en forma de cuadros, uno para cada una de las cinco fuerzas, y luego de cada cuadro breves comentarios respecto del valor puntual que obtuvo cada componente en la asignación de valores por parte de la opinión calificada del grupo de enfoque. 


\subsection{1.- AMENAZA DE INGRESO DE NUEVOS COMPETIDORES}

Como muestra el cuadro 1, el perfil competitivo en cuanto a amenaza de nuevos competidores presenta un valor de rango medio de la escala definida (y no lejos del límite superior de tal rango medio). Se destacan el buen desempeño del sector en cuanto a economías de escala, efectos de la curva de aprendizaje y acceso a materias primas, con valoraciones óptimas. Como contrapunto, son bajos los desempeños en ventaja de costos y recursos y aranceles y restricciones comerciales, con valorizaciones apenas por encima del umbral mínimo; y ya en el mínimo acceso canales de distribución.

Los componentes que aseguran la posición en esta fuerza competitiva están marcando una protección sólida para el sector ante ingreso de nuevos competidores, amparada en las inversiones y el expertise necesario que debe afrontar quien tenga por propósito ingresar al sector como competidor; al ser un sector sensible a la escala productiva que se debe alcanzar, al tiempo de aprendizaje que es necesario hacer transcurrir operando en él, y a las importantes inversiones para cubrir requerimientos en cuanto a la estructura necesaria de lógistica y distribución. 


\begin{tabular}{|l|c|}
\hline \multicolumn{2}{|c|}{ AMENAZA DE INGRESO DE NUEVOS COMPETIDORES } \\
\hline \multirow{2}{*}{ Ítems / Variables } & $\begin{array}{c}\text { Valuación de perfil } \\
\text { competitivo (1 a 5) }\end{array}$ \\
\hline Economías de escala & 5 \\
\hline Ventaja de costos y recursos & 2 \\
\hline Efectos en la curva de aprendizaje & 5 \\
\hline Preferencia de marca & 4 \\
\hline Requerimiento de capital & 3 \\
\hline Acceso a canales de distribución & $\mathbf{1}$ \\
\hline Políticas reguladoras & 2 \\
\hline Aranceles y restricciones comerciales & 5 \\
\hline Acceso a materias primas & 30 \\
\hline \multirow{2}{*}{$\begin{array}{l}\text { Valuación de atractividad / } \\
\text { Perfil competitivo }\end{array}$} & MEDIO \\
\cline { 2 - 3 } & ALTO $>36$ \\
\hline
\end{tabular}

Cuadro 1. Amenaza de ingreso de nuevos competidores

\section{Comentarios sobre cada componente}

- Economías de escala (5). Todos los nuevos competidores que podrían satisfacer la demanda se analizaron como si se tratasen de sectores de otros países, por tanto se considera la escala máxima para este punto; la correspondiente a un sector productivo completo de todo un país que sería así productor competidor de la producción argentina. Una buena economía de escala de la competencia aumenta la amenaza de que entren a competir en el mercado italiano de manera más marcada, por eso su valor es máximo.

- Desventaja de costos y recursos (2). Los países europeos están exentos de pagar derechos aduaneros, lo que daría un valor mayor en este punto y alentaría que incursionen en el mercado italiano; como atenuante, el tipo de cambio haría que los 
costos en pesos argentinos fueran pequeños, siendo una ventaja para el sector productor argentino.

- Efectos en la curva de aprendizaje (5). En el caso presente la producción solo tendría que expandirse hasta cubrir una nueva cuota de mercado en Italia, por tanto se interpreta que la curva de aprendizaje ya alcanzó su máximo. Toda competencia potencial tendría que afrontar tal curva de aprendizaje, ya recorrida por el sector productivo local, lo que implica un claro factor promotor de sostenimiento de ventaja competitiva.

- Preferencia de marca (4). No obstante considerar que nuevos competidores provendrían del ámbito de la eurozona, los que tendrían ventajas esenciales por la proximidad producción-destino; se interpreta preferencia cultural por productos argentinos en tanto atributo de marca esencial (el concepto cuero argentino), lo que supone un buen desempeño a cuanto a perfil competitivo del sector nacional respecto de este componente relacionado con faceta simbólica de marca.

- Requerimiento de capital (3). Puntaje intermedio para este componente, que combina lo perjudicial del costo inherente al stock de maquinaria de procesamiento que todo nuevo competidor debe procurarse; con lo favorable para ellos de contar con divisas fuertes para tal adquisición. En otras palabras, ingresar al sector implica fuertes inversiones en stock de maquinaria, pero buena parte de ellas pagaderas en monedas fuertes que resultan ser las monedas domésticas de los potenciales ingresantes.

- Acceso a canales de distribución (1). Posibles competidores ubicados en el ámbito de la Unión Europea y en Suiza (proximidad máxima al mercado destino la de competidores potenciales de este país), contarían con preferencia en los canales de distribución lo que les daría una gran ventaja competitiva; por lo tanto, es el menor puntaje para el componente desde el punto de vista del perfil competitivo del sector productor argentino. En otros términos, es una amenaza concreta para la competitividad del sector productor argentino la plena disponibilidad de canales de 
distribución por parte de potenciales ingresantes al sector bajo el supuesto de que estos provengan primordialmente de la zona europea.

- Políticas reguladoras (3). Las políticas de regulación del mercado destino favorecerían en principio a posibles competidores ingresantes de ese origen, aunque no resulta hoy un impedimento de relevancia para el sector productor argentino el cumplir con toda la normativa que hace al movimiento de productos en el mercado europeo; por lo tanto, se valora al componente con valor intermedio desde la perspectiva de su relevancia a ventaja competitiva.

- Aranceles y restricciones comerciales (2). Los potenciales ingresantes del ámbito europeo cuentan con grandes ventajas respecto a aranceles, por eximición o beneficios puntuales respecto de ellos, solo compensado por normativas de acuerdo puntuales en la relación bilateral que se está considerando, potenciado por perspectiva a futuro de convenios específicos Unión Europea-Mercosur, todo lo cual, impide que al componente se le asigne el valor más bajo desde la perspectiva del perfil competitivo del sector productivo argentino.

- Acceso a materia prima (5). La mejor posición relativa de Argentina en cuanto a resursos naturales y materias primas inherentes a la producción del sector bajo estudio, respecto de países origen de quienes puedan ser posibles ingresantes, determina un valor de rango óptimo en la comparación del componente específico de acceso a dichas materias primas. Se da en este caso una consolidación de la ventaja comparativa argentina como fundamento de creación en concreto de ventaja competitiva.

\subsection{2. - INTENSIDAD DE RIVALIDAD ENTRE COMPETIDORES}

En cuanto a la fuerza competitiva intensidad de rivalidad entre competidores, el perfil competitivo del sector se ubica en un rango medio, con amarillo en semaforización y también en posición intermedia en cuanto al valor específico de 23 (con límites del rango medio para la fuerza entre valores de 14 y 28). En este caso el perfil se sustenta en -si bien no óptimos- valores asignados que marcan buen desempeño en los 
componentes cantidad de competidores, crecimiento de la demanda, barreras de egreso altas y productos indiferenciados; teniendo esto como contra partida la débil posición puntual en cuanto a estrategias de baja de precios y costos de sustitución bajos.

\begin{tabular}{|l|c|}
\hline \multicolumn{2}{|c|}{ RIVALIDAD ENTRE COMPETIDORES } \\
\hline Ítems / Variables & $\begin{array}{c}\text { Valuación de perfil } \\
\text { competitivo (1 a 5) }\end{array}$ \\
\hline Cantidad de competidores & 4 \\
\hline Crecimiento de la demanda & 4 \\
\hline Baja de precios & 5 \\
\hline Costos de sustitución bajos & 2 \\
\hline Pérdida de posición de empresas & 3 \\
\hline Barrera de egresos altas & 4 \\
\hline Productos indiferenciados & 4 \\
\hline \multirow{2}{*}{$\begin{array}{l}\text { Valuación de atractividad / } \\
\text { Perfil competitivo }\end{array}$} & 26 \\
\hline & MEDIO \\
\hline
\end{tabular}

Cuadro 2. Intensidad de rivalidad entre competidores

\section{Comentarios sobre cada componente}

- Cantidad de competidores (4): La gran cantidad de competidores en el mercado de destino, sean productores de la propia región europea o incluso de países vecinos a Argentina, como Brasil, estimula la rivalidad competitiva, generando fuerzas que según prescribe el modelo analítico seguido incrementa la competitividad del sector producto de cueros vacunos.

- Crecimiento de la demanda (4): El crecimiento de la demanda resulta ser un factor complementario del de la cantidad de competidores y la rivalidad que generan, en 
el sentido generar estímulo para una mayor producción que se estimará que encontrará lugar en una demanda creciente del producto.

- Baja de precios (5): Desde la perspectiva de las exportaciones argentinas, la relación en el tipo de cambio entre moneda doméstica débil y moneda foránea del país de destino fuerte, favorece la posición competitiva del sector exportador, ante el margen del que dispone para utilizar el elemento "precio del producto exportado en país de destino" como factor que fomenta la competitividad del sector exportador. Además, la misma relación en el tipo de cambio protege al sector doméstico ante guerras de precios que se puedan desatar en el contexto internacional de la comercialización del producto. Por todo, el de baja de precios es un componente particularmente favorable para la competitividad del sector exportador argentino.

- Costo de sustitución bajo (2): El de cuero vacuno es un sector no caractarizado por altos costos de sustitución inherentes a una relación comercial productorcomprador, lo que debilita la posición competitiva de productores ante compradores que detentan para sí una posición fuerte en ese sentido dada por facilidad de la que suelen disponer si es que desean o necesitan cambiar de proveedores. Si bien no es un producto esencialmente indiferenciado, es cierto que el cuero vacuno no cuenta con la posibilidad de agregarle el suficiente valor para que haga de una oferta comercial algo muy costoso de sustituir. Por lo tanto, el componente de costo de sustitución resulta ser un punto débil para la posición competitiva del sector exportador.

- Perdida de posición de empresas (3): Las empresas están mayoritariamente atomizadas con porcentajes que no llegan al $10 \%$ en la mayoría de los casos. Sin embargo, existen muchas empresas que han ido perdiendo posiciones y por tanto dejando mucha capacidad operativa ociosa, lo que hace que aumente la rivalidad ante la imposibilidad de utilizarla en los procesos productivos. Los niveles de capacidad ociosa y la atomización de competidores generan un valor solo intermedio para este componente considerado en la valorización de posición competitiva para el sector. 
- Barreras de ingreso altas (4): El curtido y producción del cuero exige para su operación una alta cantidad de maquinaria, instalaciones, inversiones en logística y demás compromisos de capital físico y financiero como para operar. Esto supone una importante barrera a franquear para todo competidor que analice su ingreso al sector como productor. No obstente, es cierto que competidores de algunos sectores específicos pueden aprovechar una integración de sus cadenas productivas y desembarcar de ese modo en la producción de cueros vacunos. Por la consideración de ambas cuestiones, es que se valoriza con una buena posición, aunque no la óptima, el componente de barreras de ingreso como determinantes de la posición competitiva del sector exportador.

- Productos indiferenciados (2): Dada las propias características del producto físico del sector, con dificultades evidentes para diferenciar la oferta, la posición es débil en cuanto a la diferenciación de productor en tanto factor generador de ventaja competitiva; de allí que se califique como se lo hace al componente en cuestión.

\subsection{3.- PRESIÓN DE COMPETIDORES SUSTITUTOS}

La fuerza competitiva presión de competidores sustitutos cuenta con solo tres componentes para analizar, y en los tres el perfil competitivo del sector se muestra insuficiente. Tal lo arrojado por el relevamiento, el perfil llega a un rango medio con valor específico de 7, pero muy cercado al umbral de 6 debajo del cual el perfil ya se mostraría como de mal desempeño. Resultado de esto es el comportamiento insuficiente en los tres componentes de la fuerza, tal como muestra el cuadro 3. 


\begin{tabular}{|l|c|}
\hline \multicolumn{2}{|c|}{ PRESIÓN DE COMPETIDORES SUSTITUTOS } \\
\hline \multirow{2}{*}{ Ítems / Variables } & $\begin{array}{c}\text { Valuación de perfil } \\
\text { competitivo (1 a 5) }\end{array}$ \\
\hline Mejora de la funcionalidad & 5 \\
\hline Facilidad de acceso & 3 \\
\hline Precio & $\mathbf{2}$ \\
\hline \multirow{2}{*}{$\begin{array}{l}\text { Valuación de atractividad / } \\
\text { Perfll competitivo }\end{array}$} & 10 \\
\cline { 2 - 2 } & MEDIO \\
\hline & ALTO $>12$ \\
& BAJO < 6 \\
\hline
\end{tabular}

Cuadro 3. Presión de competidores sustitutos

\section{Comentarios sobre cada componente}

- Mejora de la funcionalidad (5): Desde el punto de vista de criterios estrictos de uso, los productos sustitutos del cuero vacuno "natural" cumplen aceptablemente con los requerimientos exigidos por las industrias que conforman a los compradores del producto. Ahora bien, la condición de calidad y el valor simbólico asociado a un "cuero legítimo" no es algo sencillo de imitar para productor sustitutos, identificando a estos últimos primordialmente como los cueros sintéticos. Por lo tanto, el componente de funcionalidad y el mencionado valor simbólico otorgan al cuero natural una valoración óptima para la posición competitiva del sector productivo.

- Facilidad de acceso (3): El componente está relacionado con la facilidad con la que los compradores pueden acceder a la oferta de los productores-vendedores de productos sustitutos. Por las cuestiones simbólicas y de funcionalidad expresadas en el ítem anterior, y por la difícil disponibilidad de proveedores alternativos, es que al componente se le asigna valor intermedio respecto de cuánto aporta a la posición competitiva del sector. 
- Precio (2): Los productos sustitutos al cuero vacuno natural tienen en el precio casi el único factor a partir del cual poder atacar posiciones competitivas, en un mercado que valora muy especialmente el componente "natural" del producto. Dada la flexibilidad en las opciones de producción de las alternativas sintéticas, los productos sustitutos tienen gran margen para manejar el componente precio como maniobra competitiva para aboradar mercados asistidos por cuero naturla, de allí la calificación que se otorga a tal cuestión en tanto amenaza para la posición competitiva del sector.

\subsection{4.- PODER DE NEGOCIACIÓN DE CLIENTES}

Igualmente en rango medio se muestra el perfil competitivo del sector para la fuerza poder de negociación de clientes, con valor cuantitativo puntual ubicado a su vez en posición intermedia del rango amarillo desde el punto de vista de la semaforización (valor de 25, para un rango intermedio de con valores límite de 16 y 32). Se puede notar que mientras ningún componente alcanza valor óptimo de 5 , los de costo de sustitución (1), amenaza de integración (2), participación en facturación total (3) y concentración de compradores (3), muestran claramente valores insuficientes que permiten explicar el valor intermedio para toda la fuerza. 


\begin{tabular}{|l|c|}
\hline \multicolumn{2}{|c|}{ PODER DE NECOCIACIÓN DE CLIENTES } \\
\hline \multirow{2}{*}{ Ítems / Variables } & $\begin{array}{c}\text { Valuación de perfil } \\
\text { competitivo (1 a 5) }\end{array}$ \\
\hline Participación en facturación total & 4 \\
\hline Costo de sustitución & 4 \\
\hline Diferenciación de producto & 2 \\
\hline Concentración de compradores & 3 \\
\hline Relación con la calidad & 4 \\
\hline Disponibilidad de información & 2 \\
\hline Amenaza de intergración & 5 \\
\hline Nivel de utilidades & 2 \\
\hline \multirow{2}{*}{$\begin{array}{l}\text { Valuación de atractividad / } \\
\text { Perfil cómpetitivo }\end{array}$} & 26 \\
\hline & MEDIO \\
\cline { 2 - 2 } & ALTO $>32$ \\
\hline
\end{tabular}

Cuadro 4. Poder de negociación de clientes

\section{Comentarios sobre cada componente}

- Participación en la facturación total (4): El destino del cuero como producto es muy variado, lo que hace que existan numerosos clientes intermedios y, por tanto, que el peso que cada uno tenga en forma individual sobre la facturación de quienes producen sea mínimo. Del mismo modo el poder de negociación de clientes, al ser muchos y estar atomizados, ejercen un poder sobre los productores de cuero irrelevante.

- Costo de sustitución (4): Son elevados los costos de sustitución de proveedores argentinos del producto en caso de que clientes elijan sustituirlos por otro origen de la provisión, lo que implica que un cambio esté relacionado con mayores costos de producción. En este componente vuelve a tallar la relación entre moneda doméstica débil del productor respecto de la moneda fuerte del comprador. Por lo tanto, todo cambio implica la compra de un producto competidor más caro, lo que repercute en 
toda la cadena de valor del comprador, razón por la cual el componente registra una buena valorización desde la perspectiva del perfil competitivo del productor.

- Diferenciación del producto (2): El producto es común en todas las curtiembres sin ninguna característica que lo diferencie del resto y conseguido con técnica conocida. Como no existe una diferenciación de producción marcada, no es difícil para el cliente cambiar de proveedor de cuero, ya que no tiene ninguna característica especial puntual excepto la calidad; por tanto la falta de atributos diferenciadores de la oferta incrementa el poder de negociación de los proveedores, resintiendo la posición competitiva del sector económico productor.

- Concentración de compradores (3): Si bien existen asociaciones y grupos que pueden concentrar compradores, la gran variación de productos finales que usan cuero supone que una concentración total de compradores no resultaría posible. Todo esto lleva a la asignación de valor medio para este componente de la posición competitiva del sector productor.

- Relación con la calidad (4): Los compradores son altamente sensibles a la calidad del cuero, ya que afectara directamente la calidad del producto final, y una buena calidad por parte de la competencia haría que los clientes la elijan por sobre el resto. Esto incrementa las exigencias sobre el sector competitivo, estimulándolo a mantener una oferta de calidad y enfocada en las necesidades de los compradores, lo que en virtud de las prescripciones del modelo lleva a atribuirle una calificación elevado respecto del perfil competitivo.

- Disponibilidad de información (2): En la actualidad no es difícil para el cliente intermedio contar con información sobre la empresa a la cual compra el cuero como producto. La facilidad de acceso a la información otorga ventaja al cliente al momento de negociar, aumentando su poder de negociación sobre el sector productivo y otorgando un puntaje modesto desde la perspectiva de creación de ventaja competitiva para este último.

- Amenaza de Integración (5): Es baja la amenaza de integración hacia atrás por parte de la demanda hacia el ámbito de la producción, en virtud de ser la 
producción de cuero una actividad con requerimeintos muy específicos que hace difícil que compradores pueden tomar también para sí las funciones de proveedor. En virtud de estas especificidades es que es atribuible una baja ponderación al componente de amenaza de integración hacia atrás por parte de compradores, lo que potencia la posición competitiva de los productores.

- Nivel de utilidades (2): Dado que el cuero en tanto insumo originado en producción primaria no cuenta con un gran componente de valor agregado al momento de exportarlo, es que se torna sensible todo cambio de condiciones que pueda generar la demanda, y que afecten márgenes de utilidades que no por la característica mencionado no podrá ser holgado. En consecuencia, tal poder relativo de compradores debilita la posición competitiva de vendedores-exportadores, otorgando al componente del esquema que esto registra una valorización baja.

\subsection{5.- PODER DE NEGOCIACIÓN DE PROVEEDORES}

En cuanto a la necesidad de haber dividido el análisis de la fuerza poder de negociación de proveedores en proveedores frigoríficos y proveedores productos químicos, nada hizo variar respecto de -al igual que lo ocurrido para las restantes cuatro fuerzas del esquema de análisis- la posición de rango medio del perfil competitivo del sector; en además clara mejor posición para frigoríficos respecto de productos químicos. Sobre esto último, solo en el componente importancia del cliente se observa mejor valor para proveedores de químicos que frigoríficos; mientras que en los restantes cinco componentes se muestra siempre mejor perfil relativo respecto de proveedores frigoríficos que respecto de proveedores de productos químicos. 


\begin{tabular}{|l|c|}
\hline \multicolumn{2}{|c|}{ PODER DE NECOCIACIÓN DE PROVEEDORES } \\
\hline \multirow{2}{*}{ tems / Variables } & $\begin{array}{c}\text { Valuación de perfil } \\
\text { competitivo (1 a 5) }\end{array}$ \\
\hline Concentración de proveedores & $\mathbf{2}(\mathrm{F})-\mathbf{2}(\mathrm{Q})$ \\
\hline Importancia del cliente & $\mathbf{2}(\mathrm{F})-\mathbf{2}(\mathrm{Q})$ \\
\hline Costos de sustitución & $\mathbf{2}(\mathrm{F})-\mathbf{1}(\mathrm{Q})$ \\
\hline Amenaza de integración & $\mathbf{2}(\mathrm{F})-\mathbf{5}(\mathrm{Q})$ \\
\hline Importancia de los insumos & $\mathbf{2}(\mathrm{F})-\mathbf{3}(\mathrm{Q})$ \\
\hline Inexistencia de sustitutos & $\mathbf{2}(\mathrm{F})-\mathbf{4}(\mathrm{Q})$ \\
\hline \multirow{2}{*}{$\begin{array}{l}\text { Valuación de atractividad / } \\
\text { Perfil competitivo }\end{array}$} & $\mathbf{1 2}(\mathrm{F})-\mathbf{1 7}(\mathrm{Q})$ \\
\cline { 2 - 2 } & MEDIO \\
\hline F: Frigoríficos \\
Q: Productores de químicos
\end{tabular}

Cuadro 5. Poder de negociación de proveedores

\section{Comentarios sobre cada componente}

- Concentración de proveedores (2-2): Tanto el sector de frigoríficos como el de empresas químicas se encuentra muy concentrado, con la consecuente posibilidad de ejercer poder relativo en tanto proveedores sobre el sector productor como comprador de insumos. Por lo tanto, para los dos ámbitos es baja la valoración del componente desde el punto de vista de la posición competitiva del sector.

- Importancia del cliente (2-2): En ambos casos, tanto para frigoríficos como para industria química, el sector productivo no resulta ser trascendente en términos de porcentajes de su facturación total a él atribuible, a consecuencia de lo cual se le otorga un valor modesto al desempeño del componente en la creación de ventaja competitiva del sector exportador.

- Costos de sustituir proveedores (2-1): El estar como se dijo los sectores proveedores concentrados, hace que sean pocos los actores relevantes en los 
mismos, por lo que, desde la perspectiva del sector productor-exportador como cliente, hace que el costo de sustitución de proveedores sea elevado y por tanto el componente que lo registra toma valores modestos desde la persectiva de creación de su ventaja competitiva, en peor posición para químicos que para frigoríficos.

- Amenaza de integración (2-5): Por características de procesos productivos es claramente más probable una integración hacia delante de cadenas de producción por parte de frigoríficos que de industrias químicas. En consecuencia, la relavancia del componente para la posición competitiva del sector exportador registra valor modesto para el caso de frigoríficos (movimiento probable de integración hacia adelante), y un óptimo para el de industria química (movimiento competitivo improbable de integración hacia adelante).

- Importancia de los insumos (2-3): Ambos tipos de sectores como proveedores de insumos son de vital importancia para el curtido y posterior comercialización del cuero como producto; con la salvedad de que, en los productos químicos, existiría una gama mayor de posibles químicos a implementar y por tanto su peso relativo en el componente sería menor, al igual que el poder de negociación que esto otorga a los proveedores; de allí la diferencia en valoración registrada para uno u otro tipo de industria.

- Inexistencia de insumos sustitutos (2-4): Existe la posibilidad en el proceso productivo de proveerse de cuero de otro animal o de menor calidad de piel; sin embargo sería algo que afectaría directamente el producto final. En cambio los productos químicos pueden remplazarse sin afectar tanto la calidad final. Es por esta mayor dependencia de calidad del cuero que permite a los proveedores "frigoríficos" tener un mayor poder de negociación respecto de los proveedores de insumos químicos, de allí la desigual asignación de valor para el componente se trate del ámbito frigoríficos (posición que amenaza la ventaja competitiva del sector exportador) o del ámbito industria química (posición que no afecta tanto a tal ventaja). 


\section{2- Análisis de la creación de ventaja competitiva}

Tal como recién se hiciera con el análisis de las fuerzas del escenario competitivo, se analiza ahora en base a los datos relevados la posición competitiva del sector en estudio respecto de los elementos del diamante de la competitividad, bajo la mencionada lógica de semaforización, en lo atinente a -se recuerda-condiciones de los factores, condiciones de la demanda, estrategia, estructura y rivalidad entre empreas, sectores relacionados y de apoyo y rol del gobierno. Se procede en el análisis de esta sección del mismo modo que en el anterior, en cuanto a notar una impresión general, en este caso sobre cada elemento del diamante, y luego la expresión de comentarios sobre cada cuestión puntual, en función de lo que surgiera del relevamiento de datos; todo, no obstante, será ahora de asignación de valores cualitativos, que en esencia poco cambia respecto del análisis que fue posible realizar.

\subsection{1.- CONDICIONES DE LOS FACTORES}

En el elemento del diamante de la competitividad sobre condiciones de los factores se deja ver el buen desempeño sobre algunos de los componentes relacionados con la tradicional ventaja comparativa del país respecto de las condiciones para la producción de ganado, al igual que ocurre con componentes como calidad de materias primas e infraestructura para faena y para transporte, del mismo modo que el potencial de crecimiento de producción que a futuro es de seguir esperando para todo lo que sea producción primaria. Como contrapartida, se notan las falencias en todo lo que sea agregaciones de valor sobre la cadena de producción primaria, sea por condiciones de componentes esenciales como la infraestructura de puertos, o bien cuestiones como la de investigación y desarrollo o todo lo que sea reflejo de capacidad de gestión (organizativa/productiva de productores o bien para agregar valor a la producción pecuaria). 


\begin{tabular}{|c|c|}
\hline \multicolumn{2}{|c|}{ CONDICIONES DE LOS FACTORES } \\
\hline ítems / Variables & $\begin{array}{c}\text { Valuación de perfil } \\
\text { competitivo }\end{array}$ \\
\hline Calidad de las materias primas & ALTO \\
\hline Disponibilidad de áreas para crianza de animales & MEDIO \\
\hline Infraestructura para faena & MEDIO-ALTO \\
\hline Infraestructura para transporte & ALTO \\
\hline Infraestructura de puertos de exportación & MEDIO-BAJO \\
\hline Interreaciones entre industria cárnica y de curtiembre & MEDIO \\
\hline Instituciones de investigación y desarrollo & MEDIO-BAJO \\
\hline Capacidad organizativa/productiva de productores pecuarios & MEDIO-BAJO \\
\hline Capacidad producción pecuaria p/ agregar valor a prod. de cueros & MEDIO-BAJO \\
\hline Potencial de crecimiento de la producción de cueros & MEDIO-ALTO \\
\hline
\end{tabular}

Cuadro 6. Condiciones de los factores

Desde el punto de vista de las condiciones de los factores, la creación y/o sostenimiento de ventaja competitiva puede esperarse entonces en los componentes que se derivan de las ventajas comparativas del tipo de producción, quedando en términos relativos algo rezagados los que hacen tanto a una inversión en infraestructura necesaria para valorizar la cadena productiva, como lo atinente a la capacidad de gestión de los procesos productivos y de logística exportadora.

\subsection{2.- CONDICIONES DE LA DEMANDA}

En cuanto al elemento del diamente condiciones de la demanda, se muestra de lo relevado una clara docotomía en cuanto a nivel de exigencia y potencial de crecimiento tanto de la demanda doméstica como de la foránea. En efecto, los niveles de exigencia se posicionan en calificaciones altas, pero como contrapartida lo hacen en posiciones bajas los potenciales de crecimiento esperados para ambos tipos de demanda. Por su parte, muestra niveles medios tanto la diversidad del tipo de industria que en mercado de destino demanda al cuero como insumo, como la existencia en el mismo mercado de productos que funcionen como sustitutos para tal insumo. 


\begin{tabular}{|c|c|}
\hline \multicolumn{2}{|l|}{ CONDICIONES DE LA DEMANDA } \\
\hline ítems / Variables & $\begin{array}{c}\text { Valuación de perfil } \\
\text { competitivo }\end{array}$ \\
\hline Nivel de exigencia de demanda local s/ calidad de los cueros & ALTO \\
\hline Potencial de crecimiento de la demanda local & BAJO \\
\hline Nivel de exigencia de la demanda italiana de cueros argentinos & ALTO \\
\hline Potencial crecimiento de la demanda italiana de cueros argentinos & MEDIO-BAJO \\
\hline Diversidad del tipo de industrias demandantes cueros argentinos & MEDIO \\
\hline Existencia en merc.italiano de productos sustitutos a cueros argentinos & MEDIO \\
\hline
\end{tabular}

Cuadro 7. Condiciones de la demanda

Parece ser el cuero argentino un tipo de producto de calidad reconocida, que sabe encontrar demanda exigente que estimula la competitividad del sector productivo. Ahora bien, la existencia de demanda exigente parece darse también bajo condiciones de bajo crecimiento en cuanto a volumen de tal demanda, generando la dicotomía que lo que impulsa el factor calidad a la ventaja competitiva del sector, lo degrada el factor volumen ante las perspectiva a fututo de bajo crecimiento.

En un punto intermedio en cuanto a potencial de creación de ventaja competitiva se encontraría lo que haría a movimientos en pos de flanquear la limitación al ritmo de crecimiento de la demanda, en la forma de encontrar demandas alternativas a un producto juzgado como de muy buena calidad. En este punto, sería modesto el potencial sobre la competitividad del sector relacionado con su capacidad de encontrar nuevos segmentos de demanda o incluso nichos estratégicos que permitan ser explotados mediante la colocación puntual en mercado de destino del cuero argentino en tanto exportable de alta calidad.

\subsection{3. - ESTRATEGIA, ESTRUCTURA Y RIVALIDAD ENTRE EMPRESAS}

En cuanto al elemento del diamante referido a estrategia, estructura y rivalidad entre empresas, tiene a la capacidad instalada y al grado de utilización de la cadena productiva como único componente de buen desempeño para el perfil competitivo del sector, mientras que otros tres componentes registran claramente un desempeño 
insuficiente, como en base a lo relevado se muestra respecto de la rivalidad entre productores por ganar cuota del mercado, la asimilación de tecnología en la cadena productiva y el perfil económico-financiero de las principales empresas del sector. Es este elemento del diamante congruente con lo visto respecto de rivalidad entre competidores de la sección anterior, respecto del ámbito doméstico del escenario competitivo.

\begin{tabular}{|c|c|}
\hline \multicolumn{2}{|c|}{ ESTRATEGIA, ESTRUCTURA Y RIVALIDAD EMPRESAS } \\
\hline ítems / Variables & $\begin{array}{c}\text { Valuación de perfil } \\
\text { competitivo }\end{array}$ \\
\hline Concentración o dispersión en poder relativo de productores locales & MEDIO \\
\hline Rivalidad entre productores por ganar cuotas de mercado a competidores & BAJO \\
\hline Grado de integración de cadena productiva de la producción de cueros & MEDIO \\
\hline Capacidad instalada y grado de utilización de cadena productiva & MEDIO-ALTO \\
\hline Asimilación de tecnología para produc. y comercializ. de cueros argentinos & MEDIO-BAJO \\
\hline Perfil económico-financiero de los principales actores del sector & BAJO \\
\hline
\end{tabular}

Cuadro 8. Estrategia, estructura y rivalidad de empresas

Analizando el elemento, se puede afirmar sobre él que la ventaja se sustenta en el proceso productivo del sector, con la plena utilización de la capacidad instalada que reporta beneficios directos en las curvas de aprendizaje a lo largo de toda la cadena de producción en el expertise inherentes a los actores del sector.

Como contraparte, la debilidad en el elemento parece encontrarse en la asimilación tecnológica y en el ámbito en el que se desenvuelven las condiciones económicas y financieras de los actores. Sobre ambas cuestiones, se puede afirmar que reciben la ingerencia desfavorable de las condiciones macro del país, con sus permanentes condiciones inestables que no hacen fácil tanto la implementación de un proceso de permanente incorporación de nueva tecnología productiva y de gestión, como un desempeño efectivo y estable de los productores que no sean tan sensible a las tan variables condiciones del macroentorno. 


\subsection{4.- SECTORES RELACIONADOS Y DE APOYO}

Dentro del elemento del diamante de sectores relacionados y de apoyo, se destaca solo el nivel de desarrollo de sectores italianos proveedores de insumos y servicios como componente que tracciona en favor de la ventaja competitiva del sector bajo análisis, algo a todas vistas no alcanza como para compensar posiciones insuficientes para los restantes seis componentes del elemento. En esto último, destaca especialmente el bajo desarrollo de sectores locales proveedores de insumos y servicios, la infraestructura de producción a puerto y la calidad de servicios financieros, componentes todos de bajo desempeño que hacen al ámbito más macro del sector.

\begin{tabular}{|c|c|}
\hline \multicolumn{2}{|l|}{ SECTORES RELACIONADOS Y DE APOYO } \\
\hline Ítems / Variables & $\begin{array}{c}\text { Valuación de perfil } \\
\text { competitivo }\end{array}$ \\
\hline Nivel de desarrollo de sectores locales proveedores de insumos y servicios & BAJO \\
\hline Nivel de desarrollo de sectores italianos proveedores de insumos y servicios & ALTO \\
\hline Calidad infraestructura desde punto producción hacia puerto de exportación & BAJO \\
\hline Calidad infraestructura desde puerto de exportación hasta mercado destino & MEDIO \\
\hline Calidad de servicios de administración aduanera & MEDIO \\
\hline Calidad de servicios financieros que asisten a proceso de producción-exportación & BAJO \\
\hline Calidad de instituciones científicas que asisten a proceso producción-exportación & MEDIO-BAJO \\
\hline
\end{tabular}

Cuadro 9. Sectores relacionados y de apoyo

Entonces, lo expresado sobre el elemento anterior respecto de las condiciones de macroentorno afecta claramente a los productores también en este otro. En efecto, promueve la ventaja competitiva los factores que hacen a sectores relacionados y de apoyo que se encuentran en el mercado de destino, en el tramo final de la cadena logística exportador-importador. Por el contrario, funciona como lastre de la ventaja competitiva todo lo que hace al ámbito "local" de tal cadena, con sectores relacionados y de apoyo que en el ámbito doméstico sufren las mismas condiciones macro que los productores, y poco pueden por tanto ser, a partir de ello, impulsores de ventaja competitiva para el sector productor-exportador de cuero vacuno. 


\subsection{5.-ROL DEL GOBIERNO}

En cuanto al último elemento analizado del diamante, muestra el rol del gobierno en dos facetas claramente contrapuestas. Por un lado, como fomentando la ventaja, la presión impositiva, que en términos relativos no resulta elevada para el sector; la política/sistema de aranceles a la exportación, que se encuentra en línea con el componente anterior; y además el nivel de relaciones comerciales bilaterales entre país productor y comprador dentro del vínculo binacional estudiado. Como contraparte, restringen la creación de ventaja competitiva las políticas de promoción a la producción de cueros, los niveles de servicios públicos que utiliza el sector para su giro comercial habitual, y los acuerdos comerciales multi o bilaterales que promuevan la producción del sector en el país, más allá de los ya mencionados con el país de destino de la relación bajo análisis.

\begin{tabular}{|l|c|}
\hline \multicolumn{2}{|c|}{ ROL DEL COBIERNO } \\
\hline \multicolumn{1}{|c|}{ Ítems / Variables } & $\begin{array}{c}\text { Valuación de perfil } \\
\text { competitivo }\end{array}$ \\
\hline Presión impositiva & ALTO \\
\hline Política/Sistema de aranceles a la exportación & ALTO \\
\hline Políticas de promoción de la actividad productora de cueros & BAJO \\
\hline Nivel de servicios de org. públicos al servicio de cadena de producción/exportación & BAJO \\
\hline Acuerdos comerciales multi o bilaterales que promuevan la exportación de cueros & BAJO \\
\hline Nivel de relaciones comerciales entre Argentina-Italia y Argentina-Unión Europea & MEDIO-ALTO \\
\hline
\end{tabular}

Cuadro 10. Rol del Gobierno

En otros términos, dentro del elemento rol del Gobierno impulsarían la ventaja las cuestiones más generales relacionadas a las políticas públicas que deben acompañar a toda actividad exportadora, y la retrasarían las cuestiones más puntuales que hacen a las especificidades del sector económico bajo estudio en tanto generador de actividad exportadora que requiere políticas y/o soluciones gubernamentales en forma puntual. 


\section{3- Comentarios sobre el perfil competitivo del sector analizado}

La información relevada primordialmente en el grupo de enfoque especialista de la relación bilateral argentino-italiana, y con el que se analizó las especificidades del sector productor y exportador de cuero vacuno, permitieron explorar en un perfil competitivo este último en el marco de tal relación.

Desde la perspectiva del análisis del escenario competitivo, se observó que respecto de las cinco fuerzas que lo componen, en todas ellas el sector registra un desempeño de los calificados como medio dentro de las escalas de rangos de valoración que se definieran para cada una de ellas; con la característica saliente que en forma puntual sobre la fuerza "poder de negociación de proveedores", la valorización apenas alcanza al umbral del rango medio, en el límite como para que el desempeño ya sea calificado de bajo.

El análisis del escenario competitivo tiene más que ver con el entorno micro del sector productivo bajo análisis. De los treinta y tres componentes en total que se consideraron para las cinco fuerzas, surgen comportamientos de todo tipo. Reparando en la calificación de medio en las cinco fuerzas, se podría pensar a priori en muchos de los desempeños puntuales registrando muy bajo indicadores. Sin embargo, no es tan así, ya que por caso mientras son siete los componentes que registran el valor óptimo de " 5 " para el perfil competitivo del sector, solo uno obtiene el menor valor de "1" en la escala definida.

Las economías de escala, las curvas de aprendizaje, el acceso a materias primas, la posibilidad de usar en beneficios del sector maniobras competitivas en torno a los niveles de precios, el bajo desempeño comparativo de productos sustitutos, y la improbabilidad de integraciones hacia adelante y hacia atrás para el sector proveedor y cliente, respectivamente, apuntalan con desempeños óptimos el perfil competitivo. Por el contrario, el punto más bajo en desempeño competitivo puede observarse en el acceso a canales de distribución por parte de nuevos competidores (con fácil acceso y siendo por tanto amenaza competitiva latente para el sector) y en los costos de sustitución de proveedores (puntualmente respecto de industrias químicas, cuyos proveedores resultan ser difíciles de reemplazar). 
Por su parte, sobre el análisis de creación de ventaja competitiva, y a resultas de la exploración en el esquema de diamante competitivo, más relacionado con el entorno macro del sector exportador bajo estudio en la relación bilateral estudiada, se pudo observar como en los cinco elementos del diamante se registran desempeños tanto altos como bajos de acuerdo a las escalas cualitativas definidas al efecto. Lo que al parecer tracciona impulsando la ventaja competitiva está en la calidad de la materia primas y en la infraestructura del transprote a disposición del sector, dentro del elemento condición de los factores; en el nivel de exigencia de las demanda del producto tanto sea la doméstica como la foránea; en la capacidad instalada y el grado de utilización de la cadena productiva desde el punto de vista de la estrategia, estructura y rivalidad de las empresas; en el nivel de desarrollo de proveedores en el punto de destino de las exportaciones, eso en cuanto al elemento sectores relacionados y de apoyo; y por último en la estructura impositiva en la sede de origen de las exportaciones, que no resulta ser particularmente gravosa pensando en las cuestiones que hacen al rol del Gobierno en tanto determinante de la creación de ventaja.

Desde el otro extremo, lo que retrasa la creación y/o sostenimiento de ventaja competitiva parece estar en las cuestiones relacionadas con la gestión de componentes de apoyo a lo esencial del sector productivo, tal lo que se muestra sobre capacidad organizativa de productores y asistencia en investigación y desarrollo, todo para la condición de los factores; en el bajo potencial de crecimiento de la demanda, tanto la doméstica como la del mercado de destino, pensando en las condiciones de tal demanda como elemento del esquema de diamante; en la baja rivalidad de competidores y en la posición económica y financiera de ellos dentro de lo que es el elemento estrategia, estructura y rivalidad de empresas; en el nivel de desarrollo de proveedores locales de insumos y servicios y en la calidad de los servicios financieros que asisten al proceso productico desde el punto de vista de los sectores relacionados y de apoyo; y por último, a la calidad de políticas públicas específicas para el sector y la baja promoción de acuerdos comerciales con otras naciones en lo que respecta al rol del Gobierno. 


\section{7-Conclusiones}

En el marco de lo que fuera el cumplimiento del primero de los objetivos específicos, se analizó en el trabajo la cadena de comercialización de cueros argentinos con destino al mercado de exportación de Italia, en el marco de la relación comercial bilateral que mantienen ambos países. De lo relevado por medio del grupo de enfoque, se desprende que siempre ha existido un interés comercial bilateral entre Argentina e Italia, siendo muestra de ello, precisamente, la existencia de organismos como la Cámara de Comercio Italiana en la República Argentina (fuente del relevamiento sobre opinantes calificados realizado para el estudio).

En este sentido, haciendo uso de la valorización por rangos de valores en el primero de los modelos, o de la valoración cualitativa del segundo, se pudieron identificar factores relevantes determinantes de fortaleza y debilidades de la cadena de valor que permite exportar al mercado de destino el producto del sector que fuera objeto de estudio. De esta forma, se dio también cumplimiento del segundo de los objetivos específicos formulados, relacionado precisamente con la identificación de tales factores.

Resultado del análisis fueron los datos presentados en la sección anterior, encuadrados en el uso de dos modelos conceptuales universalmente aceptados en tanto herramientas analíticas, tal como fuera formulado en el tercero de los objetivos específicos, y que son tanto el análisis del perfil competitivo del sector con el modelo de las cinco fuerzas competitivas, como el del diamante competitivo que analiza los elementos impulsores o retardadores de la creación y/o sostenimiento de ventaja competitiva.

Se recordará asimismo que como cuarto objetivo específico se propuso la sugerencia de una solución a la problemática inherente a la relación comercial bilateral vigente, centrada claro está en lo que se desprende del tipo de relevamiento llevado a cabo con opinantes calificados en grupo de enfoque, y sobre el sector productivo analizado. Pues bien, como conclusión respecto de los tres primeros objetivos y 
sugerencias respecto del cuarto, se presentan los siguientes ítems a modo de conclusiones, recomendaciones y comentarios finales:

- Siempre ha existido un interés comercial bilateral entre Argentina e Italia, motivado por la historia en común entre ambos países. Esto se manifiesta, por ejemplo, en la existencia de organismos como la Cámara de Comercio Italiana en la República Argentina. En virtud de la necesidad de mejora que en vistas del estudio requiere el sector productivoexportador estuadiado, bien se podrían incrementar/fomentar las relaciones comerciales bilaterales, con sustento en tipos de organismos como el mencionado en cuanto a actores relevantes que puedan promover los vínculos.

- Tomando en cuenta que el cuero vacuno en la forma en que se exporta no contiene una gran propoción de valor agregado, bien podría enriquecerse la oferta agregando valor, mejorando el producto terminado y las condiciones existentes en toda la cadena productiva y de exportación. Como ejemplo de esto último, valga la mención del grupo de enfoque en cuanto a problemas del producto en el origen, en forma de un cuidado despreocupado de los animales que provoca "daños" en lo que como producto final terminará siendo el cuero vacuno.

- Del mismo modo, podría mejorarse en todo cuanto implica el cumplimiento de normas de calidad y de la regularidad en los plazos de entrega. El de cumplimiento de plazos y regularidad en la calidad de las entregas es de las problemáticas más mencionadas en el relevamiento, siendo por tanto un ámbito susceptible de ser pensadas para él todo tipo de mejoras.

- Del relevamiento sobre los opinantes calificados surgen impresiones en torno a que el cliente en el mercado de destino resulta ser muy selectivo en sus demandas. En esta circunstancia, existen antecedentes de productos argentinos que se han ganado una sólida posición en el 
mercado italiano y hoy son preferidos por sobre cualquier otra oferta competidora. Tomando esto en cuenta, la relación comercial bilateral en torno a la exportación de cuero vacuno podrían trabajar una mayor fidelización de la demanda extranjera profundizando la presencia en nichos de aquél mercado, y perfeccionando las virtudes inherentes al producto terminado, al proceso productivo en Argentina y a todo el encadenamiento logístico para asegurar lo exportable en destino.

- Precisamente sobre esto último, se observan problemas de relevancia en todo lo que implica en transporte por vía marítima, en relación a no tener una balanza de importación-exportación equilibrada. En virtud de ello, una mejora factible estaría presente en un uso compartido del transporte marítimo con otros países, como por caso puede darse perfectamente en el ámbito puntual del Mercosur, o bien con emprendimientos conjuntos con exportadores argentinos que para otros productos requieran similar tipo de logística de transporte internacional.

- Las cuestiones referidas al tipo de cambio, presentes en varios de los componentes de los esquemas analíticos, son determinantes de ventajas que ofrecen una moneda doméstica débil (peso) respecto de la foránea fuerte (euro o dólar). Ahora bien, la contraparte de esta circunstancia es la dificultad para mantener al día a todo el proceso productivo en cuanto a inversiones en tecnología y maquinaria, requerida para asegurar el valor de la oferta y toda ella primordialmente de origen importado. Financiamiento específico para estas necesidades de capital bien podrían ser solución a estos requerimientos de mantener actualizado tanto tecnología como equipos de producción en concreto.

- En base a lo indicado por el grupo de enfoque, y reparando puntualmente en lo expresado en la sección anterior respecto del esquema de análisis del escenario competitivo, se pueden destacar esencialmente las siguientes cuestiones: 
- No es desfavorable la posición competitiva respecto del ingreso de nuevos competidores, con puntos fuertes en componentes como las economías de escala que exige el proceso productivo, las curvas de aprendizaje con ellas relacionadas y la disponibilidad de acceso a materias primas; cuestiones todas que resultan un impedimento puntual a todo intento de ingreso al escenario competitivo por parte de nuevos competidores potenciales. Como contrapunto, el acceso a canales de distribución (fundamentelmente en los últimos eslabones de la cadena logística, ya en territorio europeo) y la política de aranceles y restricciones (que benefician en forma directa a los competidores potenciales europeos) resultan ser auténticas ventanas estratégicas en las que apalancarse por parte de nuevos actores para una competencia potencial. Acuerdos a nivel países, en el marco de la relación bilateral, bien podrían ayudar a remover las amenazas que implican estas posiciones favorables a competidores potenciales en el ámbito europeo.

- La rivalidad entre competidores es otro punto fuerte del escenario competitivo, con sólidas posiciones en el conveniente uso que puede hacerse de las políticas de precios (productores que soportan bien guerras de precios) y una combinación de sector productor caracterizada por altas barreras al ingreso de nuevos competidores (no resulta algo sencillo realizar las inversiones necesarias en capital de trabajo y know-how para comenzar a ser un competidor con aspiraciones de relevancia en el sector). La rivalidad entre competidores como estímulo a la competitividad del sector se resiente en lo indiferenciado de los productos y los consecuentes bajos costos de sustitución por parte de los clientes. Trabajar en mejoras puntuales que agreguen valor y diferencien los productos podrían ser medidas concretas para paliar estas deficiencias. 
- En cuanto a la amenaza de competidores que puedan atacar posiciones del mercado con productos sustitutos, es bien clara la conclusión: el sustituto por excelencia son los cueros sintéticos, que cuentan con la evidente ventaja del menor precio, y la también evidente desventaja de su menor calidad. Trabajar puntualmente en mejoras que impliquen un enriquecimiento de la oferta vía una mayor diferenciación del producto (producto que en esencia ya se diferencia claramente de los sustitutos mencionados) y un más alto valor agregado, supondría una creación puntual de barreras estratégicas ante las amenazas latentes de sustitución. En otras palabras, el cuero vacuno tiene características instrínsecas que lo hacen diferente, de una innegable mayor calidad; pues bien, todo lo que ayude a enriquecer y/o resaltar tal característica esencial creará barreras concretas antes competidores potenciales que basen sus estrategias en ofertas con sustitutos.

- La posición competitiva del sector exportador estudiado tiene también una posición media en cuando al poder de negociación de clientes; como pudo observarse, con picos de fomento a la ventaja competitiva en la dificultad que enfrentaría algún económico que, en tanto cliente, quisiera integrarse hacia atrás ingresando el escenario competitivo de la producción, movimiento que dada las circunstancias del ámbito de producción-exportación se considera altamente improbrable (implicaría por caso la transformación en productor-exportador de clientes con base en el entorno europeo del mercado de destino, algo a todas vistas muy poco probable). Asimismo, la posición competitiva ante clientes se sustenta en que estos se encuentran dispersos, no sindo pocos en número, lo que lleva a que no representen en forma puntual altas proporciones en la facturación total de productores-exportadores, siendo además elevados para clientes los costos implícitos de cambiar de 
proveedor (cambio de productor-exportador que provee el cuero en el mercado de destino). Como contraparte, la posición ante clientes encuentra debilidades en la baja diferenciación del producto y en los márgenes de utilidad con que habitualmente operan en su giro comercial los productores-exportadores. Sobre esto, un punto de mejora puntualmente relevante podría estar en la ya mencionada necesidad de enriquecer la oferta, lo que entre otras cuestiones exigiría una mejora en atributos inherentes al producto que podrían diferenciarlo claramente, incrementando los costos implícitos para clientes ante sustituciones en la provisión que puedan llegar a plantearse (en los hechos, implicaría por caso trabajar en la profundicación del concepto simbólico cuero argentino, posicionado en la demanda pero siendo un concepto aún no debidamente explotado).

- En cuanto al esquema de análisis del escenario competitivo, se menciona como última conclusión lo observado respecto al poder de negociación de proveedores, ítem puntual que tuviera la particularidad de ser distinguido entre proveedores frigoríficos e industria química. En general, ante ambas perspectivas, la posición competitiva del sector es débil, estando los valores relevados apenas en los umbrales como para ser considerados valores "medios". La posición es más débil incluso ante frigoríficos, con todos los valores muy bajos, por riesgo en la relación de productores-exportadores con ellos ante concentración de proveedores, importancia relativa para ellos de productores como clientes, costos de sustitución, amenazas de integración hacia adelante (muy claras éstas por cierto), la importancia que respresentan los insumos de los frigoríficos y la inexistencia de sustitutos (si no hay faena, prácticamente no habría cueros). No es tan débil la posición ante industria química, con por ejemplo un 
punto muy débil en costos de sustitución, pero al menos una posición sólida en cuanto a amenaza de integración hacia adelante (es altamente improbable que un proveedor de industria química integre el negocio de producción-exportación de cueros). En línea con los comentarios de solución/mejora expresado en los otros ítems, en el de proveedores bien se podrían reforzar posiciones fortaleciendo la presencia de todo el conjunto de productoresexportadores en tanto actores de relevancia en el mercado del ganado, máxime si se piensa que implicaría solo la situación dentro del mercado doméstico, por ser el ámbito en que se desarrolla la parte de la cadena productiva que tiene que ver con la provisión de insumos.

- Finalmente, respecto del diamante competitivo como el otro gran esquema de análisis utilizado para procesar lo relevado en el grupo de enfoque, se puede concluir con lo mencionado en los siguientes ítems:

- De los cinco elementos del esquema, es de esperar que la creación/sostenimiento de ventaja competitiva se sustente primordialmente en la condición de los factore, en las condiciones de la demanda (interna y externa) y en el rol del Gobierno en tanto actor con potencial para impulsar la ventaja competitiva. Como contraparte, los elementos que al parecer menos aportan a la ventaja competitiva son la estrategia, estructura y rivalidad de las empresas, y los sectores relacionados y de apoyo.

- Concluyendo respecto de soluciones/mejoras puntuales, atinentes en forma diversa a los cinco elementos del esquema de diamante competitivo, se puede reparar en base a lo relevado que existe una oportunidad estratégica en inversión/promoción de la infraestructura de puertos y todo lo relacionado con la logística de salida de los productos. Puertos "más limpios" implicarían menores costos y más efectividad en entregas, condiciones que hacen a una 
fidelización de la demanda externa, de la mano de una recepción regular y sin demoras de los insumos que para ella representand el producto exportado.

- Las mejoras en la cadena logística bien se puede complementar con otras paralelas en la propia fase de producción, cuestión relacionada a todo fomento que pueda dársele a la producción pecuaria. En esto, es también primordial el rol del Gobierno como actor central impulsor de políticas púlicas que promuevan la actividad del sector pecuario.

- Promover una mayor inversión en investigación y desarrollo en el sector bien podría ser otro de los puntos de mejora, con el beneficio de cuestiones que actuan sobre toda la cadena productiva y sobre todos los elementos del diamante competitivo. En este sentido, desde el Estado como política puntual hacia el sector, o mismo desde éste último, se pueden generar programas específicos que impliquen el desarrollo de actividad conjunta entre los sectores productivo, académico y de la administración del Estado.

- Otra faceta en la que se podría trabajar en línea con lo recién expresado tendría que ver con la incorporación y asimilación de nueva tecnología, que eficientice el proceso productivo, generando ventajas tecnológicas a disposición del sector productorexportador.

- Con políticas puntuales para el sector no se podrían mejorar por sí mismas las condiciones macro que tiene el entorno económico local; pero bien podría trabajarse en condiciones que aseguren una mayor calidad de servicios finacieros y bancarios para el sector, cuestión clave en toda actividad exportadora, y que mejoraría las condiciones en las que hoy desempeña su actividad el sector pecuario productor-exportador. 
- De la mano de esto último, una solución puntual podría reservarse al desarrollo de proveedores, estableciendo con ellos convenios de colaboración a largo plazo que aseguren la provisión de insumos para la actividad en condiciones más predecibles y con regularidad.

- Y como solución más "macro" de entre estas mencionadas en forma casi aleatoria, se puede destacar la necesidad de establecer nuevos, o reforzar los existentes, convenios comerciales de colaboración entre países, que promuevan las relaciones bilaterales, en el ámbito de las consideradas en este trabajo (puntualmente, la relación argentino-italiana), o incluso en la ampliación hacia otras con otros países, o bien en el marco de acuerdos multitaleras y hasta entre bloques comerciales (viene a mención sobre esto la ventana estratégica que implicaría para el sector un acuerdo Mercosur-Unión Europea).

Como palabras finales, queda por mencionar la oportunidad que existe de profundizar un estudio sobre la producción y exportación de cuero vacuno en el marco de la relación bilateral argentino-italiana, que pueda abordar una tarea investigativa con inmersión al campo de estudio que enriquezca la visión que pudo tenerse en este trabajo, generada en la opinión calificada del grupo de enfoque que se alcanzó a constituir. Del mismo modo, podría enriquecerse el estudio con acceso directo a lo que saben los clientes del producto en mercado destino; pero no dejando de ser todas cuestiones que exceden con creces los límites que debieron fijarse para la presente investigación.

Queda planteado además el desafío, dirigido a todos los actores relevantes en el sector económico estudiado, de enriquecer una relación comercial como la argentinoitaliana, de holgada trayectoria en la historia de los dos países, y con profunda raigambre cultural y social. 


\section{8-Referencias bibliográficas}

Acemoglu, Daron y Robinson, James (2013). Por qué fracasan los países. Los orígenes delpoder, la prosperidad y la pobreza. Editorial Ariel.

Barsky, Osvaldo y Gelman, Jorge (2008). Historia del agro argentino. Desde la Conquista hasta comienzos del siglo XXI. RandonHouseMondadori

Belini, Claudio y Korol, Juan (2012). Historia económica de la Argentina. Siglo Veintiuno Editores

BUNGE, Mario (1995). Sistemas sociales y filosofía. Editorial Sudamericana

BUNGE, Mario (2012). Tratado de filosofía. Volumen 4. Ontología II: Un mundo de sistemas. Gedisa Editorial

Caballero Romero, Alejandro (2014). Metodología integral innovadora para planes y tesis. La metodología del cómo formularlos. CengageLearning

Castaldo, A.; Acero, R.; Perea, J.; Martos, J.; Valerio, D.; Pamio, J. y García, A. (2006). Tipología de los sistemas de producción de engorde bovino en la pampa argentina. Universidad Nacional de La Pampa; Zootecnología Nº 55, pp. 183-193

Coriat, Benjamín (1997). Los desafíos de la competitividad. Asociación Trabajo y Sociedad, Oficina de Publicaciones del CBC, Universidad Nacional de Buenos Aires

CHO, D.S. y H.C., MOON (2000). From Adam Smith to Michael Porter, evolution of competitiveness theory.World Scientific Publishing Co. Pte. Ltd

Ferguson, C. y Gould, J. (1990). Teoría microeconómica. Fondo de Cultura Económica

Ferrer, Aldo (2004). La economía argentina. Desde sus orígenes hasta principios del siglo XXI. Fondo de Cultura Económica

Gerchunoff, Pablo y Llach, Lucas (2003). El ciclo de la ilusión y el desencanto: un siglo de políticas económicas argentinas. Editorial Ariel.

Giberti, Horario (1961). Historia económica de la ganadería argentina. Ediciones del Solar

Hax, Arnoldo y Majluf, Nicolás (1997). Estrategías para el liderazgo competitivo. Ediciones Granica

Hernández Sampieri, Roberto; Fernández Collado, Carlos y Baptista Lucio, María del Pilar (2014). Metododología de la investigación (sexta edición). McGraw Hill Education

López, Andrés y Ramos, Daniela (2008). La industria de software y servicios informáticos argentina. Tendencias, factores de competitividad y clusters. Centro de Investigaciones para la Transformación. FLACSO-IDRC

Martini, María J. (2019). Marroquinería con utilización de materiales alternativos. Trabajo final, Licenciatura en Diseño de Indumentaria y Textil, Universidad Siglo 21

Moon, H.C, Rugman, A. y Verbeke, A. (1995). The generalized double diamond approach to international competitiveness.en Alan $\mathrm{m}$. Rugman, editor, research in global strategic management. A Research Annual; Vol. 5, pp. 97-114. 
Ohmae, Kenichi (1985). Triad Power. Harper Collins Publisher

Ohmae, Kenichi (1990). The Borderless World. Harper Collins Publisher

Porter, Michael (1981). Estrategia competitiva. Técnicas para el análisis de los sectores industriales y de la competencia. CECSA

Porter, Michael (1986). Ventaja competitiva. Creación y sostenimiento de un desempeño superior. CECSA

Porter, Michael (1991). La ventaja competitiva de las naciones. Javier Vergara Editor

Porter, Michael (2002). Cambiar el modo de competir internacionalmente. Publicado en Estrategia y Ventaja Competitiva. Ediciones Deusto

Quiroga, Eduardo (2019). La competitividad del sector cárnico argentino. Ediciones Haber

Ramírez, María D. y Wallace, Robert (1998). Competitividad, productividad y ventaja comparativa. El enfoque de negocios de Michael Porter y el de la economías nacional de Paul Krugman, una aplicación al caso de México. Investigación Económica, vol. LVIII:225, pp. 17-82

Rapoport, Mario (2010). Las políticas económicas de la Argentina. Una breve historia. Planeta Booket

RAPOPORT, MARIO. Las políticas económicas de la Argentina. Una breve historia.

Planeta Booket (2010).

Ricardo, David ([1817] 2010). Principios de economía política y tributación. Fondo de Cultura Económica (2010).

Roccatagliata, Juan A.Coordinador(2008). Argentina. Una visión actual yprospectiva desde la dimensión territorial. Editorial Emecé (2008).

Salvador, Claudio (2013). Historia de la industria curtidora argentina. Desde Salta y Tucumán hasta el Riachuelo. Editorial Dunken

Smith, Adam ([1776] 1994). La riqueza de las naciones. Economía Alianza Editorial

Taleb, Nassim (2014). El cisne negro. El impacto de lo altamente improbable. Paidós

Ungaro, Pablo (2010). La innovación en la cadena de valor del cuero vacuno para marroquineria en la Argentina y su relación con la distribución del poder. Ponencia II Congreso Iberoamericano de Investigación Artística y Proyectual 